\title{
Dynamic gene expression in fish muscle during recovery growth induced by a fasting-refeeding schedule Pierre-Yves Rescan*1, Jerome Montfort ${ }^{1}$, Cécile Rallière ${ }^{1}$, Aurélie Le Cam¹, Diane Esquerré ${ }^{2}$ and Karine Hugot ${ }^{2}$
}

Address: ${ }^{1}$ National Institute for Agricultural Research, Joint Research Unit for Fish Physiology, Biodiversity and the Environment, INRA Scribe, IFR140, Campus de Beaulieu, 35042 Rennes, France and 2CRB GADIE, INRA, DGA, Laboratoire de Radiobiologie et d'Etude du Genome, 78352 Jouy-en-Josas, France

Email: Pierre-Yves Rescan* - pierre-yves.rescan@rennes.inra.fr; Jerome Montfort - jerome.montfort@rennes.inra.fr; Cécile Rallière - cecile.ralliere@rennes.inra.fr; Aurélie Le Cam - aurelie.lecam@rennes.inra.fr; Diane Esquerré - diane.esquerre@jouy.inra.fr; Karine Hugot - karine.hugot@jouy.inra.fr

* Corresponding author

Published: 28 November 2007

BMC Genomics 2007, 8:438 doi:10.1/86/147|-2164-8-438
Received: 31 January 2007

Accepted: 28 November 2007

This article is available from: http://www.biomedcentral.com/I47I-2/64/8/438

(C) 2007 Rescan et al; licensee BioMed Central Ltd.

This is an Open Access article distributed under the terms of the Creative Commons Attribution License (http://creativecommons.org/licenses/by/2.0), which permits unrestricted use, distribution, and reproduction in any medium, provided the original work is properly cited.

\begin{abstract}
Background: Recovery growth is a phase of rapid growth that is triggered by adequate refeeding of animals following a period of weight loss caused by starvation. In this study, to obtain more information on the system-wide integration of recovery growth in muscle, we undertook a timecourse analysis of transcript expression in trout subjected to a food deprivation-refeeding sequence. For this purpose complex targets produced from muscle of trout fasted for one month and from muscle of trout fasted for one month and then refed for 4, 7, II and 36 days were hybridized to cDNA microarrays containing 9023 clones.
\end{abstract}

Results: Significance analysis of microarrays (SAM) and temporal expression profiling led to the segregation of differentially expressed genes into four major clusters. One cluster comprising 1020 genes with high expression in muscle from fasted animals included a large set of genes involved in protein catabolism. A second cluster that included approximately 550 genes with transient induction 4 to II days post-refeeding was dominated by genes involved in transcription, ribosomal biogenesis, translation, chaperone activity, mitochondrial production of ATP and cell division. A third cluster that contained 480 genes that were up-regulated 7 to 36 days post-refeeding was enriched with genes involved in reticulum and Golgi dynamics and with genes indicative of myofiber and muscle remodelling such as genes encoding sarcomeric proteins and matrix compounds. Finally, a fourth cluster of 200 genes overexpressed only in 36-day refed trout muscle contained genes with function in carbohydrate metabolism and lipid biosynthesis. Remarkably, among the genes induced were several transcriptional regulators which might be important for the genespecific transcriptional adaptations that underlie muscle recovery.

Conclusion: Our study is the first demonstration of a coordinated expression of functionally related genes during muscle recovery growth. Furthermore, the generation of a useful database of novel genes associated with muscle recovery growth will allow further investigations on particular genes, pathways or cellular process involved in muscle growth and regeneration. 


\section{Background}

Food restriction is associated with reduced growth rates. If refed, various animals including fish, grow at a faster than normal rate. During this burst of growth which mainly affects muscle, an accelerated turnover takes place which is characterized by markedly increased protein synthesis relative to degradation [1]. The elevation of protein synthesis after feeding can be translated in terms of the cellular dynamics of muscle growth. Thus, it has been shown that feeding stimulates proliferation of fish myogenic cells in vivo [2] as well as in vitro [3], providing a source of nuclei for myotube formation and fibre hypertrophy [4]. There is now evidence that muscle recovery growth results from processes of metabolic adaptation, regulated by endocrine as well as the autocrine/paracrine system notably involving IGF1 $[1,5,6]$. With the purpose of deciphering the mechanisms involved in muscle recovery growth, some studies have also reported the expression of candidate genes such as metabolic-related genes [7], dominant negative regulators of the basic helix-loop-helix (bHLH) transcription factor genes [8] and uncoupling protein 2 genes [9] during nutritional restriction and refeeding in rainbow trout. However, until now the genetic network which is mobilized in recovering muscle has not been exhaustively described. In this study we took advantage of high density trout cDNA microarrays to assess overall gene expression and to determine which pathways are dynamically activated in recovering muscle. Also we identified several genes potentially involved in the gene-specific transcriptional adaptations taking place in recovering muscle.

\section{Results}

\section{Effect of refeeding on growth characteristics}

The mean body weight of the trout was $132 \mathrm{~g} \pm 6.0$ and the condition factor was $1.6 \pm 0.03$ before fasting. At the end of the 30-days fasting period the mean body weight decreased to $121 \mathrm{~g} \pm 5.5$ and the condition factor to $1.3 \pm$ 0.03 . The mean body weight increased to $130 \pm 6.3,144 \pm$ $7.8,143 \pm 6.7$ and $183 \mathrm{~g} \pm 14$ and the condition factor to $1.4 \pm 0.02,1.5 \pm 0.05,1.5 \pm 0.03,1.6 \pm 0.02,4,7,11$ and 36 days post refeeding respectively.

\section{Changes in gene expression during a fasting-refeeding schedule: Overview}

To screen for genes involved in muscle recovery growth, we undertook a time-course analysis of transcript expression in muscle of trout fasted for one month and then refed for 4, 7, 11 and 36 days. At each time point, eight to nine fish were sampled giving in total 43 separate complex cDNA targets that were hybridized to 43 microarrays (GEO accession number: GSE6841). Unsupervised hierarchical clustering of gene expression patterns from all samples produced a consistent grouping of the samples according to the fish feeding conditions (i.e. fasting and 4 ,
7, 11 and 36 days post-refeeding) (Fig 1). This validated the experimental design and allowed further analysis. To define those genes whose expression levels were significantly different in muscle from 4, 7, 11 or 36 days refed animals compared to muscle from fasted fish we used SAM analysis [10]. We therefore obtained approximately 2200 genes that were then hierarchically clustered using an average-linkage clustering [11]. This resulted in the formation of four major clusters of genes displaying distinct temporal profiles (Fig. 2). A similar clustering was obtained when using the K-means clustering (not shown). The first cluster was composed of genes with peak expression in muscle from starved fish, the second included genes overexpressed at 4, 7 and 11 days post-refeeding and down-regulated at 36 days post-refeeding (cluster II) the third was composed of genes with a later and more sustained induction (7-36 days post-refeeding) (cluster

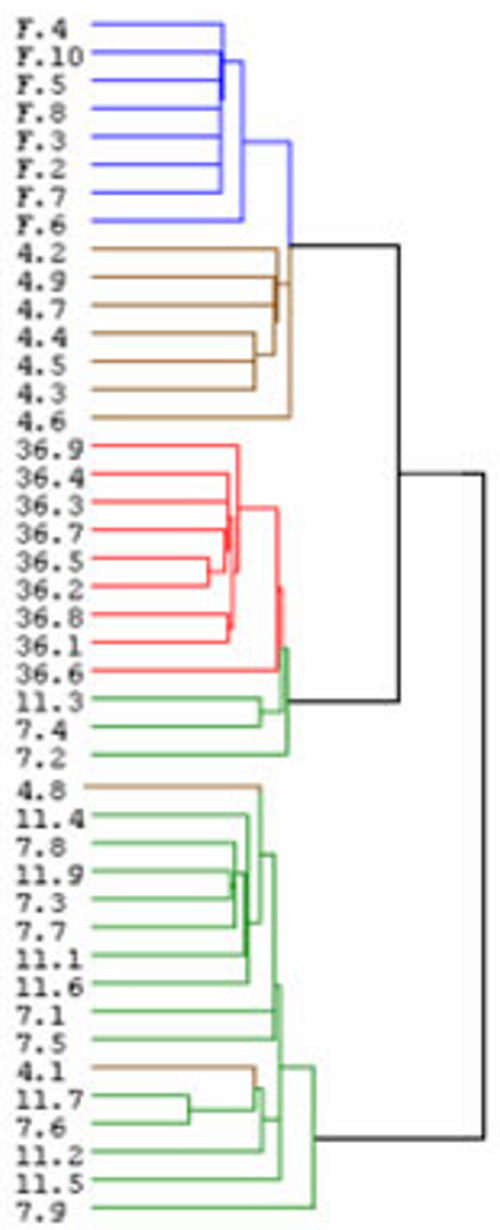

\section{Figure I}

Unsupervised hierarchical clustering consistently sorts fish muscle samples according to feeding conditions. $\mathrm{F}_{2-10}$ : muscle of distinct fasted trout, $4_{I-9}, 7_{I-9}, \mathrm{II}_{I_{-8}}$ and $36_{I-9}$ : muscle of 4 , $7, \mathrm{II}$ and 36 days distinct refed trout. 


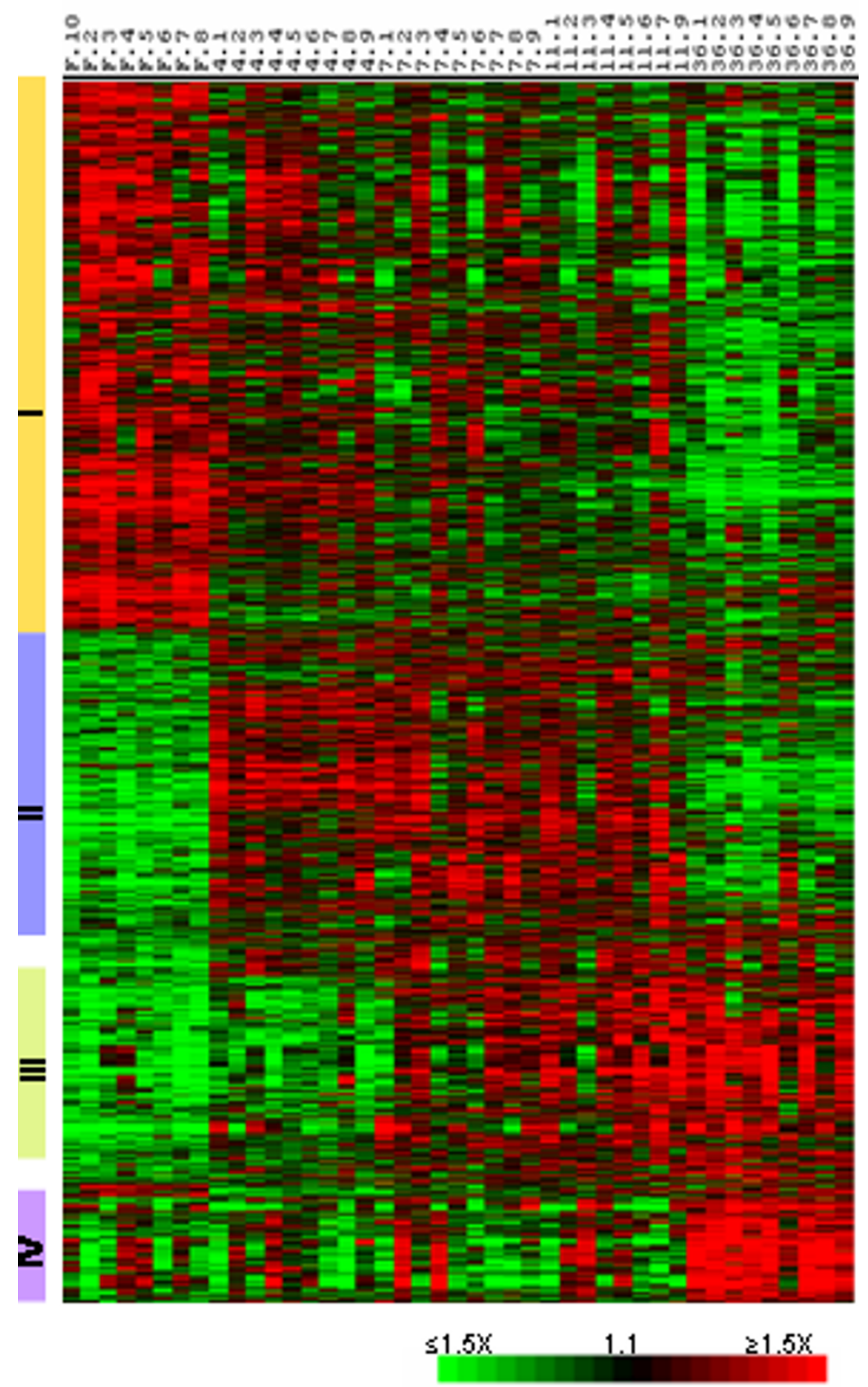

\section{Fold repressed Fold induced}

\section{Figure 2}

Supervised clustering analysis of the differentially expressed genes selected by SAM. Cluster I comprises genes up-regulated in muscle from fasted animals, cluster II includes genes with transient induction 4 to II days post-refeeding, cluster III contains genes whose expression began at 7 days post refeeding and was maintained up to 36 days post-refeeding and cluster IV contains genes up-regulated 36 days post-refeeding. Each row represents the temporal expression pattern of a single gene and each column corresponds to a single sample: columns I to 8: muscle from distinct fasted trout; columns 9 to 17, 18 to 26,27 to 34 and 35 to 43 : muscle from $4,7, I I$ and 36 day distinct refed trout, respectively. Expression levels are represented by a color tag, with red representing the highest levels and green the lowest levels of expression. 
III) and the fourth (cluster IV) contained genes overexpressed only in 36 day refed trout muscle. These expression profiles and the clusters are available online as a browseable file [12]. The accession number of each spotted clones can be obtained by typing the corresponding uniq_id (clone name) in the nucleotide data base of the NCBI.

\section{Genes with peak expression in starved trout muscle (cluster I)}

Cluster I contained approximately 1000 genes showing high expression in the muscle of fasted fish and down-regulation after refeeding. In this cluster were notably identified two major markers of nutrient deprivation: the tuberous sclerosis component 2 (TSC2) an inhibitor of mTOR function and the translational repressor 4E-BP1. The most distinctive feature of cluster I was the presence of a large repertoire of genes involved in the regulation of protein degradation (Fig. 3). These genes participate either in the lysosomal system such as the cysteine protease cathepsins $\mathrm{B}, \mathrm{D}$ and $\mathrm{S}$ or to the ubiquitin-proteasome pathway. In this latter class were several proteasome subunits, proteasome-associated proteins, ubiquitin, several ubiquitin-conjugating enzymes, ubiquitin carboxylterminal hydrolases and ubiquitin ligases. Among other genes involved in proteasome-mediated degradation were several COP9 signalosome complex subunits, cullin-3 and the Ariadne- 2 protein homolog. Notably we did not observe any significant up-regulation of calpains in the muscle of fasted trout. Cluster I contained many genes involved in catabolic pathways and beta oxidation of fatty acids such as the short, medium and long chains of AcylCoA dehydrogenase.

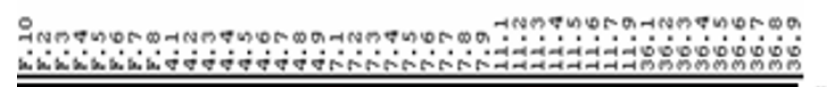

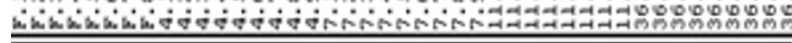
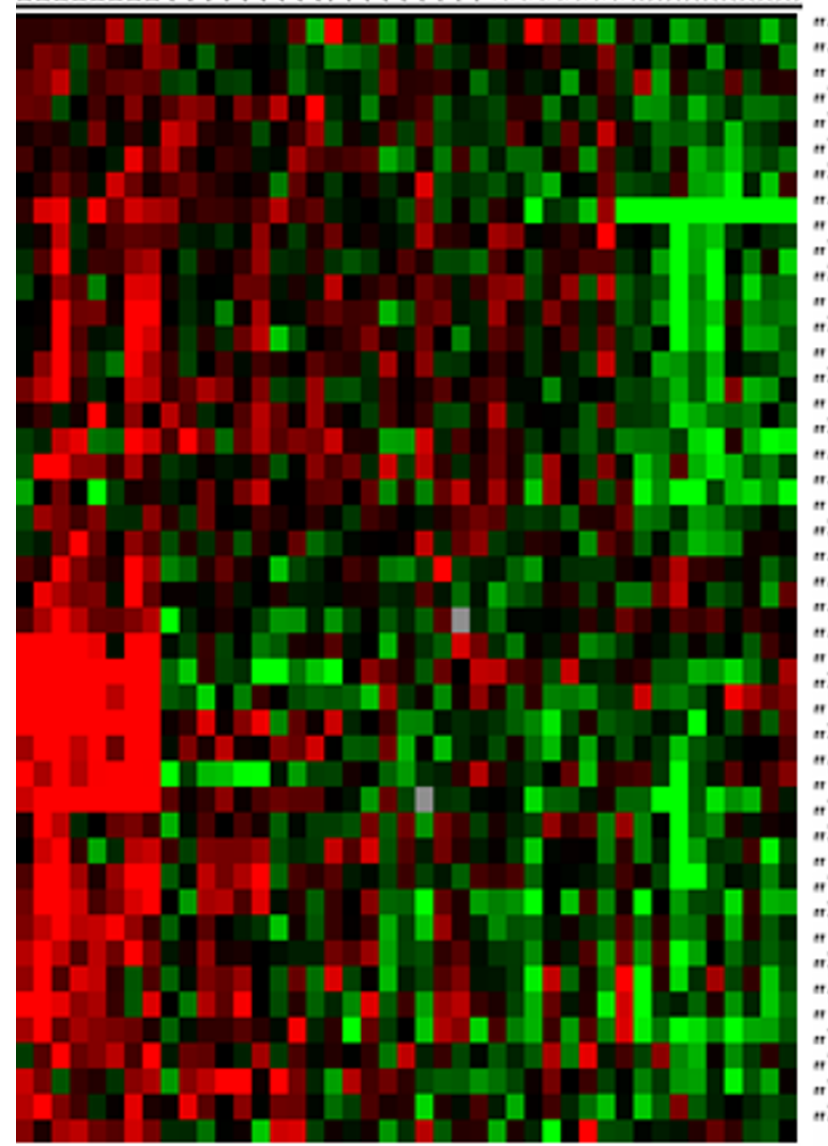

$\leq 1.5 \times \quad 1.1$

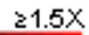

Fold repressed

Fold induced

\section{Clone name Swissprot_hit_description}

"tcav0002.d.23; Cathepsin S precursor"

"tcab0003.d.14; Ubiquitin-conjugating enzyee E2 $\mathrm{H"}$

"1RT42E1? A Cog; Ubiquitin-conjugating enzye E2-25 kDa"

"IRT99008 D T04; inkyrin repeat and SOCS box protein 9 "

"IRT100AIg I Alo: Proteasoue subunit beta type 5 precursor"

"IRT160E11- ${ }^{-}$C06: Proteasone activator conplex subunit 2 "

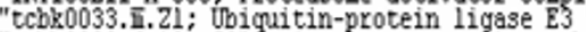

"tcblo020.f.18: Copg sigmalosoue couplex subunit ?"

"IRT15IMi1 a G06: Proteasone subunit beta type 2 "

"IRT122J24DTE12: Proteasone subumit alpha type 5 "

"cay0018.0. D7: Putative proteasone naturation factor uapl"

"IRT28012 C H06; 265 proteasoue non-ATPase regulatory subunit 12 "

"ccblo019-n-09: 26S protease reculatory subunit 7"

"IRT96M10 C G05; 265 protease regulatory subunit 4 "

"tcbl0016.2.08: Cullin-3"

"IRT118C 99 a B 5 ; toiquitin carboxyl-terninal hydrolase 12 "

"tcay0031.ō.I5; 26S proteasoue non-aTPase regulatory subunit 13 "

tcay 0005. q. 21: C0p9 signalosoue couplex subunit 8

tcad0006.1.22; 26 S protease regulatory subunit S10B "

"IRT7OA03 A A02; Itchy houlolog है 3 ubicuitin protein ligase"

"tcay0021-f:07; tobiquitin-protein ligase E3 $\mathrm{h}$ "

tcav0003. 14: 65 proteasoue non-A tpase reculatory subumit ?"

"ccay0036.1. 24; Ubiquitin carboxy1-terninal hydrolase 13 "

"tcay0003.i.0: Ubiquitin carboxyl-terninal hydrolase 28 "

"tcay0010.a.20; proteasone-associated protein ECK29 houlog "

"IRT101H16 D D08: Ariadne-2 protein hololog

"tcba0030. $\bar{e}$. T2: RIMG finger protein $24^{4 "}$

"IRT116CO4 C BO2: Cathensin B precursor "

"tcay0007. $\bar{n} .21$; Copg sionalosoue couplex subunit 2 "

"ccav0026.1.17; Tbiquitin"

"IRT139H16 D D08; COP9 sigmalosone conplex subunit 3 "

"IRT103C24-CB12: 26 S proteasone non-ATPase requlatory subumit 4 "

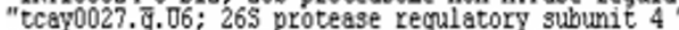

"IRT2SKO4 C FO2; ER degradation-enhancing alpha-nannosidase-like"

"IRTI03ALE C A08; Cathepsin D precursor"

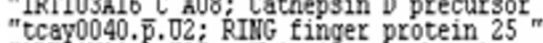

"IRT8909 A FO5: Ubiquitin carboxyl-terninal hydrolase $15 "$

"tcad0006.f-18: Tbiquitin-conjugating enzye E2 variant 1 "

"tcas0002. 14: RIMG finger protein 2"

"IRT137103 $\mathrm{A}$ E02: $26 \mathrm{~S}$ proteasone non-ATPase regulatory subunit 1 "

"1RT119.2- ${ }^{-}$

"IRT114121-A-G11; Proteasone subunit beta type 9 precursor

1RT115B23 $\mathrm{B}^{-\mathrm{A} 12}$; Ubiquitin conjugation factor $\mathrm{E} 4$ "

"IRT36006 С $\mathrm{B0} 3$; " Ubiquitin-conjugating enzye E2 G2"

tcay0012.k.22: "ubiquitin ligase protein LRSAmi "

\section{Figure 3}

Supervised clustering of SAM selected genes belonging to cluster I and involved in protein degradation. Columns as in figure 2. 
Genes up-regulated 4 to I I days after refeeding (cluster II) Cluster II included approximately 550 genes with transient induction 4 to 11 days post refeeding. In this cluster were found more than 40 genes regulating mRNA synthesis, processing and turnover (Fig. 4). Among them were genes encoding small nuclear ribonucleoproteins, transcription initiation factors, RNA helicases of the DDX family, spliceosome-associated proteins such as the NHP2-like protein 1 as well as polyadenylation and export factors.

Cluster II also comprised a large set of genes involved in various aspects of translation (Fig. 5). These genes encode translation initiation factors (including the SUI1 domain containing density-regulated protein DRP), elongation and peptide chain release factors, peptidyl-tRNA hydrolases and several aminoacyl-tRNA synthases. In addition to these genes, a large group (Fig. 6) of genes whose products regulate protein folding and maturation was also found in cluster II. Among these latter were several heat shock proteins (HSP), endoplasmin, several subunits (alpha, beta, gamma, theta, zeta and epsilon) of the chaperonin-containing complex TCP1 and seven peptidyl prolyl cis/trans-isomerases encoding genes (including genes encoding FK506-binding proteins) that are known to cat-

\section{Clone name Swissprot_hit_description}

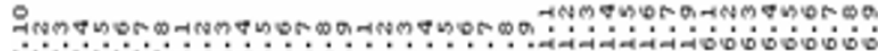

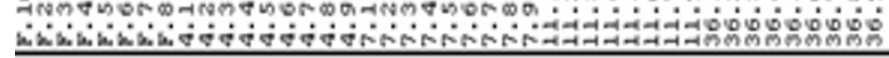

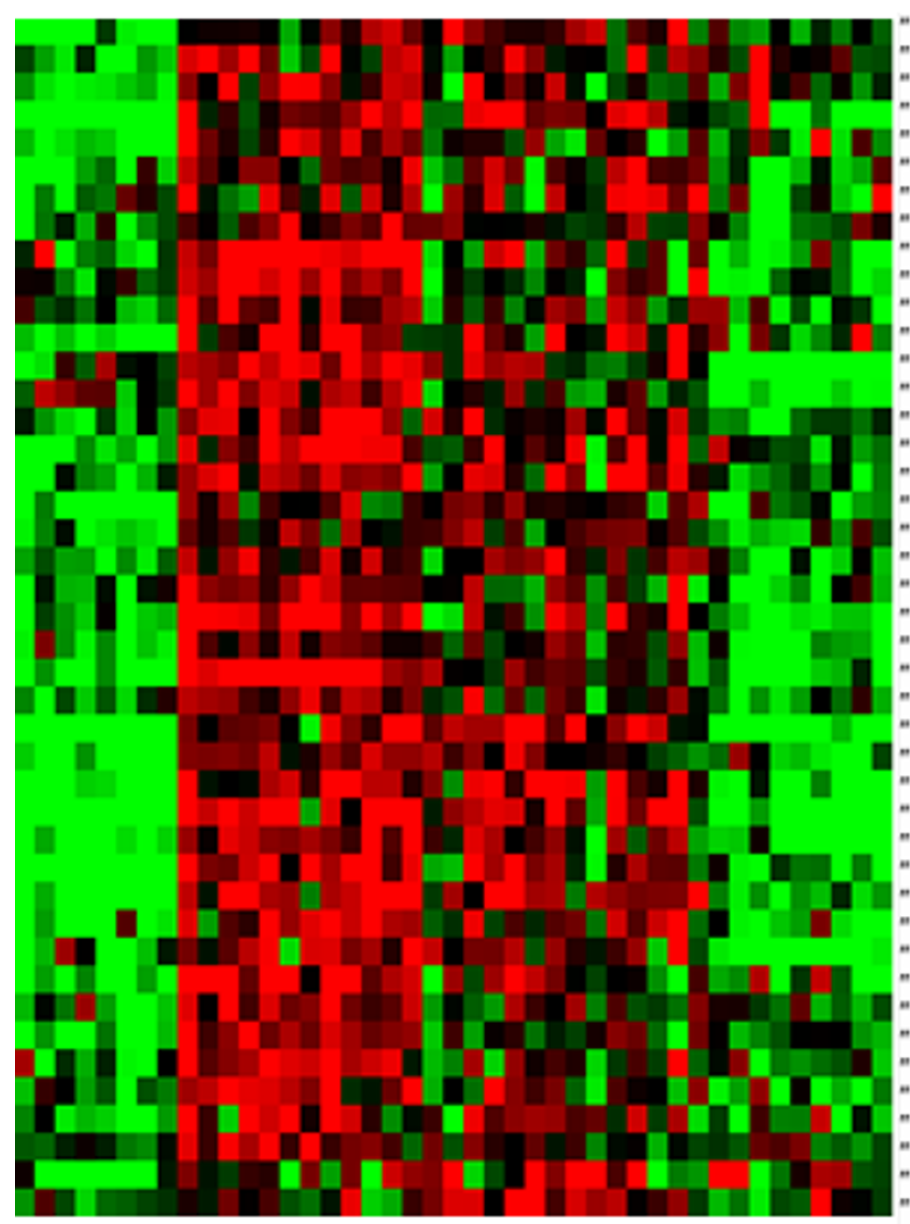

ccad0007.g.16; Sall nuclear ribonucleoprotein Sa D3 *

tcac0003.h.09; Dewelopatztally regulsted Fu-binsing protein $1^{\prime \prime}$

IRT83002 D CO1; ATP-deperdent REd helicase A "

IRT116G1 $\overline{2}$ C DO6; Sal1 waclear ribowacleoprotein $3 \mathrm{a} 02$ "

tcay0025. D. II: Regalator of noesense transcripts i"

tcok0028.1.01; Probable dT7-degendent RHh belicase Dto:27 "

tcbk0031.q.24; 04/06 sabl! nuclear tibonucleoprotein "

IRT102F09 B C05; Polperase I and transcript release tactor "

1RT89L22 $\bar{D} \bar{F} 11$; Suli moclear riborocleoprotein associated protein B' -

tcbk0042.1.19; Transcription initiation foctor IIB"

1RT9lH2 D Dil; Polyaderylate-binding protein 2 "

1RT15600\% है Q05; Pre-2Pu ptocts3ing splicing toctos 8 "

IRTSSFO3 B CO2; aWd tumower grotein 4 hoaloo"

IRT41007 A-B04; Drosone coaponent 10 "

tcba0002.c.03; Scaffold sttachatent factor B "

tcbk0001.e.18; Sall nuclear ribonucleoprotein if "

tcbk00\$6.1.10; Sall nuclear tibonucleoprotein $\mathrm{Z}$ "

tcay0003.1.02: Splicing factor $3 \mathrm{~h}$ shunit 2 "

1RT30018 C BD9; Tho conplex sutunic 4 .

tcar0030.q.03; 06 sRPh-sssocisted \$2-1ike vtotein "

IRTi56302 C Fol; Beterogeneous nuclear ribcucleoprotein $\mathrm{h} / \mathrm{B}$ "

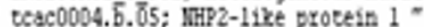

tcay0032, j.11: Sall nuclear ribonucleoprotein \$a D2 *

1RTi2TM06 C T03; Beterogeneous nuclear ribotucleoprotein H

IRT148009"B Do5; 03 sabil nucleolaz riborncleoprotein protein "

tcba0080.5. 03 ; Frogile $X$ aental retardatica symdroae-related protein $2^{*}$

tcba0004.c.11; PRP19/?S04 hosolog "

tcbk0000.k.20; US rasll waclear ribcencleogrotein conponent "

1RT115B23 B DO2; 5ylicing tactor U2Af 35 rba sulumic"

tcac0003.?.09; Splicing factot, azgimine/setine-tich $z^{n}$

tcay0010.j.15; Rth-bindisy protein vith serine-rich doasin $1^{\prime \prime}$

tory0017.h.15; Hecerogeneous malear riborseleoprotein $A D^{*}$

tcay0002.h.05; Clearage and polpaderrilatica specificity foctor"

tcac0006.c.08; Gez-agsociated protein 7 -

tcba0007.a.14; $130 \mathrm{kDa}$ lewcine-rich protein "

tcba0013.p.09; 7robable ATP-deyendent RHA belicase DWW 31 "

ccad0001.j.24; Heverogeneous malear ribowsleoprovein 0 "

tcay0015.0.17; ATP-depensent Fu helicase DOX24"

tcbk0045. j.08; Heterogeneous vaclear ribornaleoprotein $I^{\prime \prime}$

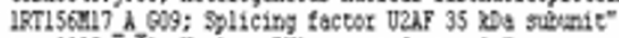

tcay0035. e. 01 ; Iuclear Na export tactor 1 "

$18 T 160003$ A Bos; Putarive RUth-binding protein 15 "

tcbk0048.j.I8; Apcescl coppleatntatice foctor "

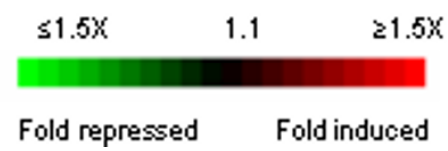

Figure 4

Supervised clustering of SAM selected genes belonging to cluster II and involved in RNA synthesis and processing. Columns as in figure 2. 


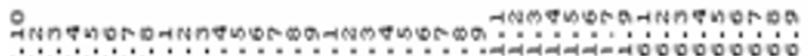

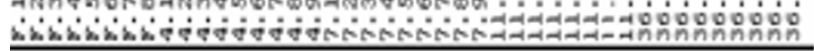

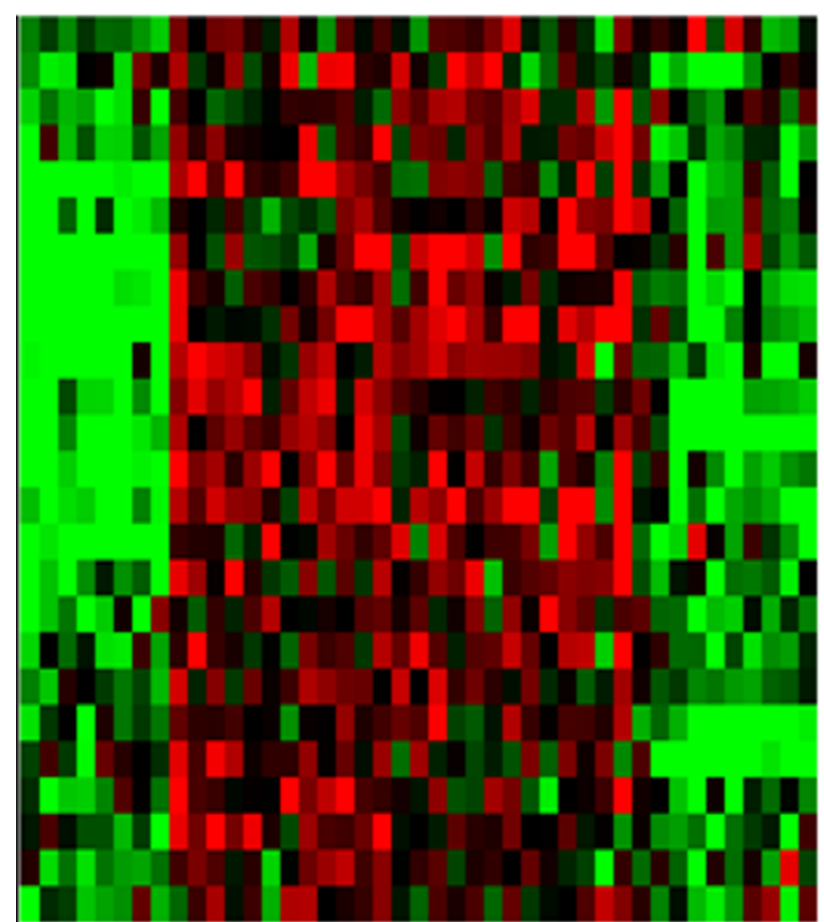

\section{Clone name Swisssprot_hit_description}

"tcba0001.b.15; Dokaryotic trenslation initiaticn factor 6 "

"IRT11380? B BD4; Eukaryotic translation initiation factor 3 submit 8 "

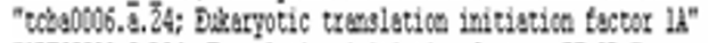

"1RT65008 C DO4; Tremslation initiatico factor elf-2B "

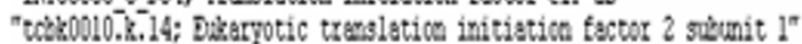

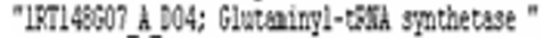

"tcha0008.

"tcry0oc1.j.03; Eukaryotic peytios chain telease factor skbmit 1"

"tcos0001.t.24; Densicr-reyulated protein"

"tcha00C1.h.03; Elocyation foctor Ts, nitockonórial precursor "

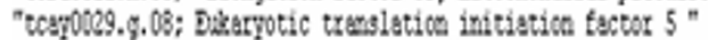

"tcor0002.a.04; Disarpotic trenslation initiatico tactor 5 "

"tckk0051.R.09; Dikarpotic trenslation initiation factor $Q$ "

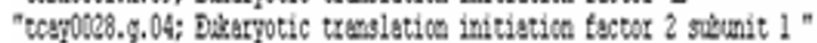

"tckk0038.p.03; Argingl-tRQ spathetase"

"tckb0013.e.02; Treenyl-tWa snthetase"

"LR29008 D I04; Eutaryotic translation initiation factor 4 gans 1 "

"tcory031.b.09; Translation initiation foctor If-2"

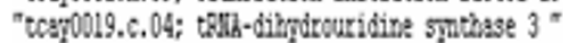

"IRTiste24 D D12; Eukaryotic translation initiation tactor 3 submic 4" "IRT60014 D Bon; Eukaryotic translation initiation factor 3 stbuit 12 "

"tcab0002.i.04; Elongation factor 1-alpha, oocyte fon "

"tcha0024.b.16; Isoleucyl-twilh srathetase"

"tcar0011.a.21; Peptióyl-tWRA brojrolase"

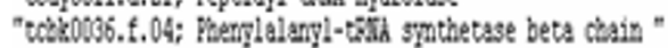

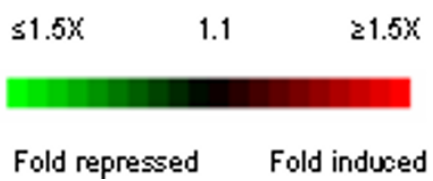

Figure 5

Supervised clustering of SAM selected genes belonging to cluster II and involved in translation. Columns as in figure 2.

alyze the cis-trans isomerization of prolyl bonds in oligopeptides and various folding states of proteins

Consistent with the induction of genes involved in protein biosynthesis, cluster II included a large number of genes involved in ribosome formation. This group of genes which is presented in Fig. 7 included structural genes encoding ribosomal proteins as well as several genes whose products regulate ribosome biogenesis among which were fibrillarin, nucleolin, Brix domaincontaining proteins, PUA domain-containing hypothetical protein MJ1432, RRp5, BMS1 and SAS 10 (something about silencing protein 10). Interestingly, in contrast to ribosomal structural genes which displayed about uniform expression during the 4 to 11 days post refeeding period, most of the genes regulating ribosome biogenesis sub-clustered together (Fig. 7, upper part) peaking at 4 days post-refeeding.
In accordance with an increase in cellular biosynthesis, a large number of genes involved in mitochondrial production of ATP grouped into cluster II (Fig. 8). Among them were several genes which are components of the oxidative phosphorylation system (chains 1, 2, 4 and 5 of the NADH-ubiquinone oxidoreductase, cytochrome $\mathrm{c}$ and ubiquinol-cytochrome c reductase complex subunits) as well as several genes of the ATP synthase complexes (alpha, beta and gamma chains). Along with these genes involved in energy production, we observed the induction of several genes important for mitochondrion formation or biogenesis such as TIM10 (a mitochondrial import inner membrane translocase), TOM34 (a mitochondrial import receptor subunit), voltage-dependant anion-selective channel protein 2 and 3 and the metalloprotease AFG3-like protein 1. Some enzymes of the mitochondrial matrix such as pyruvate dehydrogenase isoforms and succinyl-CoA ligase were also found in this cluster. Consistent with a stimulation of mitochondrial biogenesis the gene encoding the mitochondrial single-stranded DNA- 


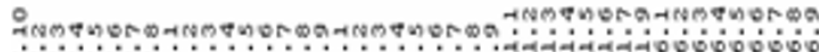

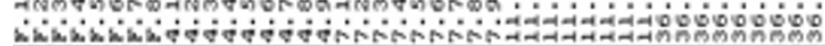

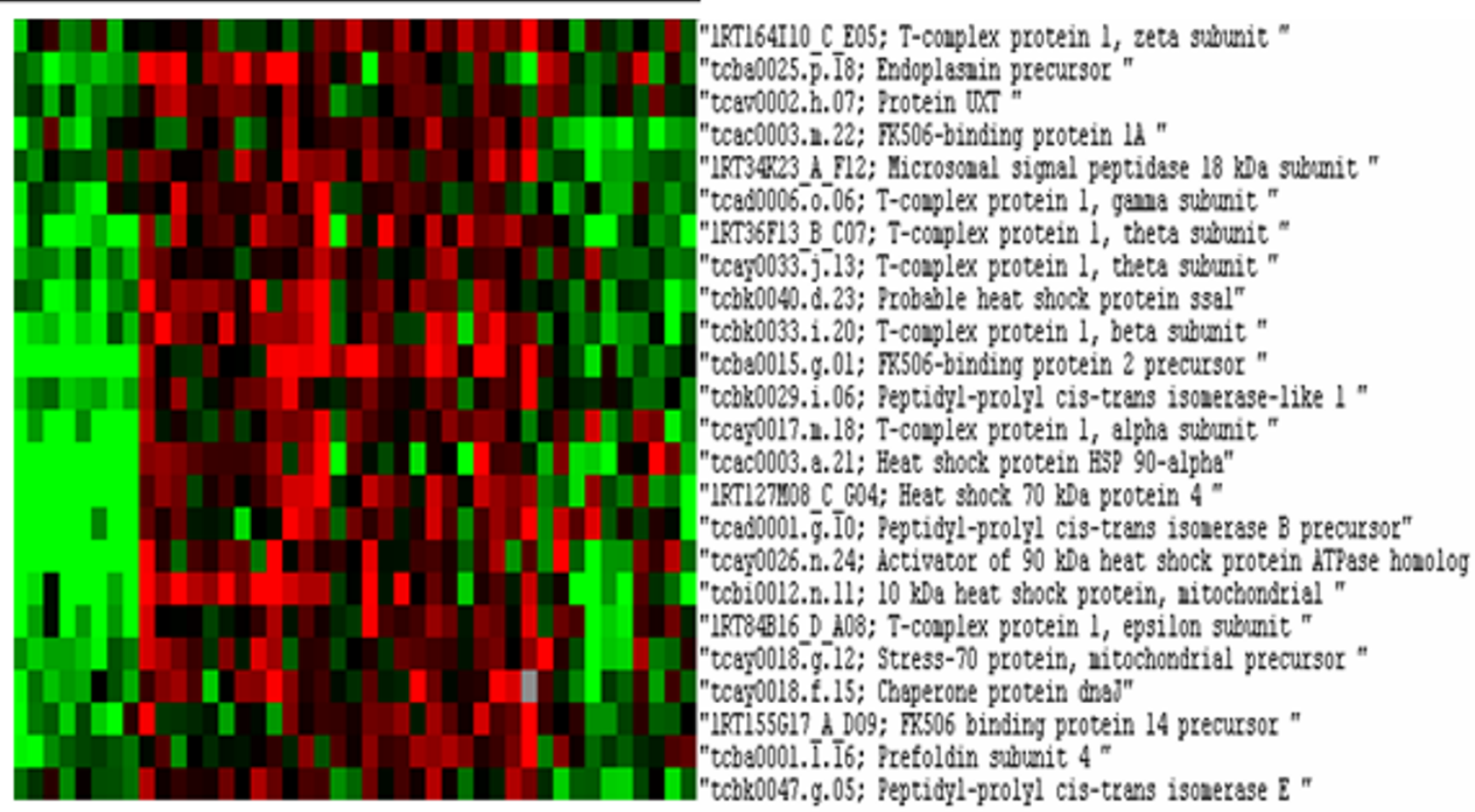

\section{Clone name Swissprot_hit_description}

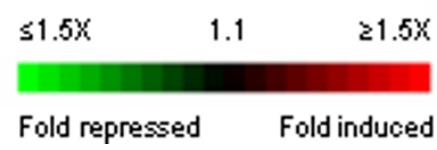

Figure 6

Supervised clustering of SAM selected genes belonging to cluster II and involved in chaperon activity. Columns as in figure 2 .

binding protein (Mt-SSB) involved in mitochondrial DNA replication was also up-regulated.

Cluster II also contained several genes characteristically expressed during cell proliferation (Fig. 9). These genes are involved in DNA replication $(\mathrm{mcm} 3, \mathrm{mcm} 6$, DNA2like homolog, DNA topoisomerase I and origin recognition complex subunit 4), progression through the cell cycle (G1/S-specific cyclin D2, CDK5 regulatory subunit, Wee1-like protein kinase, mitogen-activated protein kinase 9, M-phase induced phosphatase 2, pelota homolog and tumor protein D53 homolog), chromosome condensation (histone $\mathrm{H} 2 \mathrm{Az}, \mathrm{H} 3, \mathrm{H} 5 \mathrm{~A}$, chromobox protein homolog 3 and regulator of chromosome condensation) or associated with proliferation (protein 2G4).

Among the most differentially regulated genes with miscellaneous functions and belonging to cluster II, we found uridine-cytidine kinase 2, various genes preventing cell apoptosis such as MCL1. Genes whose products mediate
cAMP-dependant signalling such as the cAMP-dependent protein kinase beta catalytic subunit were also present. Among the genes belonging to cluster II with unknown functions we found C9orf32, the surfeit locus protein 2 and 4 encoding genes, the genes for the hypothetical protein ZK637.2 and for the hypothetical WD-repeat protein C1A6.02 in chromosome I.

\section{Genes up-regulated 7-36 days after refeeding (cluster III)}

Cluster III that contained approximately 480 genes upregulated 7 to 36 days post refeeding was enriched in genes that encode components of the reticulum and Golgi apparatus such as triadin, and exostosin-2, and proteins involved in transport from the reticulum to the Golgi apparatus including golgi SNAP receptor complex member 1 (Fig. 10). Numerous genes in cluster III function in actin cytoskeletal rearrangements (including dynactin subunit 6 , actin-like protein 3 , actin-related protein $2 / 3$ complex subunits and ankyrins) and organisation of the sarcomere (skeletal actin, myosins, tropomyosins, tro- 


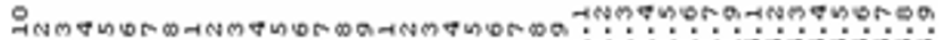

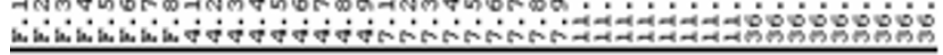

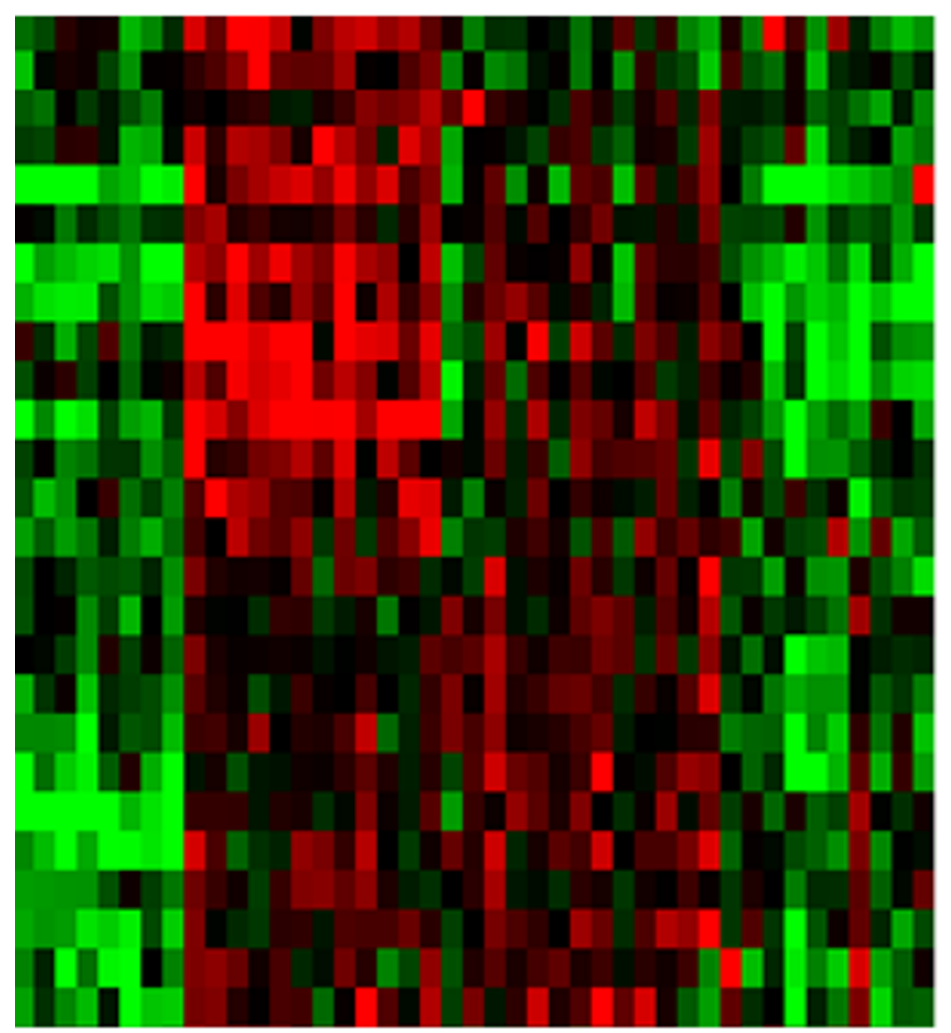

\section{Clone name Swissprot_hit_description}

\author{
tcaryon.2.15; Ribosone biogenesis grotein BSil honolog" \\ tchbioos0.1. 24: Frotein XILA0179" \\ tchic0016.p.02; Exosone coaplex excuaclease 18243 " \\ tchbo040.1.11; probable dinethylssenosine transferase " \\ 1FT78123 B E12; Brix donain containing protein 1" \\ tcoso017.i.03; Fucleolar protein $\gamma^{n}$ \\ tcer0002.g.20; Brix donsin containing protein 2 " \\ 1RT11009 A B05; Sonething about silencing protein 10 * \\ ccheoces.t.22; Nucleolar protein mos" \\ tceryo025. 0.18; SBP5 protein honoloy " \\ tcoryo09.1.24; Fibrillarin" \\ tche004.i.06; Exosone coaplex excusclease WR44. " \\ tcaro001.d.13; Jucleolin " \\ tchbouss.t.05; Ribosone biogenesis regulatory protein bonolog" \\ tcab0002.j.12; Eitochowirial 285 ribosonal yrotein 532 " \\ tchbo008.1.08; 395 ribosousl protein $\mathrm{L}^{8}$ \\ IRT144003 a BOQ; $40 S$ ribooval protein S19" \\ tchboueo. $0 . \overline{10}$; 395 ribosonal protein $111^{\prime \prime}$ \\ 1FT106F19 B C10; Iitochoctirial 285 ribosonal protein $\$ 34$ "

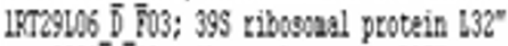 \\ tceryoco. E. 18; ribosonal protein $\mathrm{t1} 7^{\prime \prime}$ \\ tcobococe.p. 20; 285 riboscal protein $5180^{*}$ \\ tcrouse.b.16; 50S ribosoal protein $110 "$

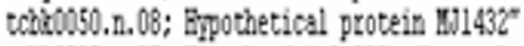 \\ tchb0010.c.15; Gitochowitial 289 ribosonal protein $\$ 6$ " \\ tceryo039.h.02; 50 ribosual protein L2"
}

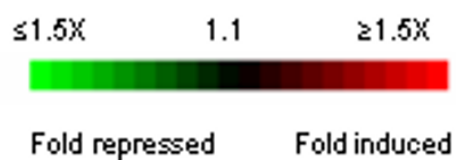

Figure 7

Supervised clustering of SAM selected genes belonging to cluster II and involved in ribosome formation. Genes regulating ribosome biogenesis segregate from genes encoding ribosomal proteins forming a subcluster peaking at 4 days post-refeeding. Columns as in figure 2 .

ponins, nebulin) (Fig. 11). Also were grouped in cluster III several collagen genes (collagen alpha 1(I), alpha 2(I), alpha 5 (IV) and alpha 1 (V) chains) that participate in the synthesis of the muscle extracellular matrix. Among the genes of cluster III with miscellaneous function were several Ras-related proteins such as Rab-24, Rab-26, and Rab$11 \mathrm{~b}$, several members of the glutathione S-transferase family, the bifunctional methylene tetrahydrofolate precursor and the myeloid leukaemia factor 1 (MLF1).

\section{Genes up-regulated in the muscle of 36 days refed trout (cluster IV)}

Cluster IV contained fewer (less than 200) genes compared to the other clusters. As observed for cluster III, cluster IV comprised several genes regulating reticulum and
Golgi biogenesis and activity such as glycosyltransferases and the protein transport Sec24D (Fig. 10). A distinctive feature of cluster IV was to contain several genes encoding glycolytic enzymes (triose-phosphate isomerase, 6-phosphofructokinase, alpha-enolase and phosphoglycerate kinase). In addition, cluster IV contained several genes involved in lipid biosynthesis such as 24-dehydrocholesterol reductase precursor, ethanolamine kinase, Scavenger receptor class B member 1 and 1-AGP acyltransferase.

\section{Functional categorization of genes contained in clusters I-IV as shown by GoMiner algorithm}

To further assess the enrichment of a particular functional class of genes in each cluster we used the GoMiner algorithm [13]. Given that the GO data bases that served as 


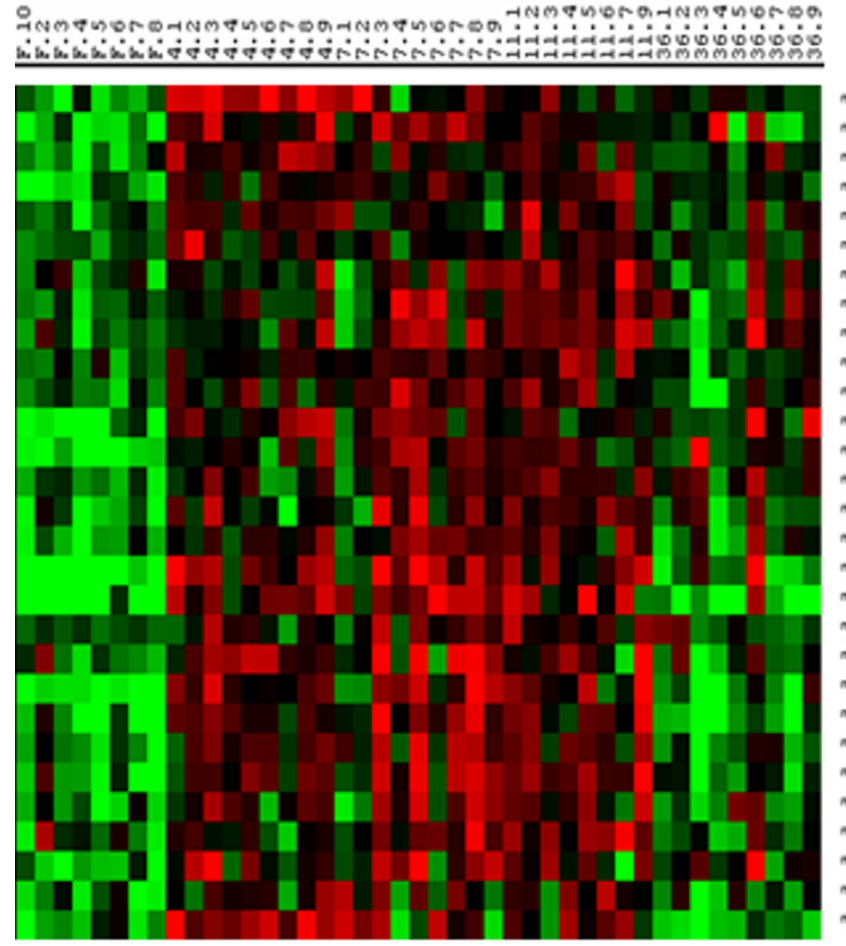

\section{Clone name Swissprot_hit_description}

"tcar0o00.d.22; Mitoctondrial inport inner aeabrase translocase subunit TIII0"

"tcbb0049.p.06; Cytochrone c oxidase subunit VIIt-related protein"

"tcba0002.a.20; Ilitochondrial inport receptor subuzit To\&34"

"LTOE04 C CO2; Chloride intracellular charnel protein 4 "

"tcblo038.t. 16; Pyruwate dehystrogenase E1 conponent alpha subunit"

"tcbk0051.i.10; 2-anino-3-ketobutrrate coenzye \& ligase"

"LRT24522 C. D11; ATP synthase beta chain"

"tcbk0029.g-03; LTP synthase gena chain"

"LRT4G4; LTP synthase beta chain"

"tcbb0048.a.02; hldehyde dehydrogenase tanily 7 aenber $\mathrm{Al}^{\prime \prime}$

"IRT161504 D E02; Yoltage-dependent anion-selective channel protein 2 "

"tcbk0010. p. ō?; Art3-1ike protein 1"

"tcad0007.j.17; 7oltage-dependent anion-selective channel protein 3 "

"1RT83R24 C F12; Succinyl-Cod ligase"

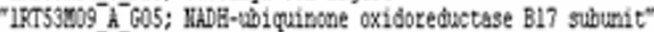

tcba0008.n.13; tbiquinol-critochroat-c teductase conplex core protein $2^{n}$

"tcba0028.b.07; Cyrochrone $c^{7}$

"tcbk0023.1.19; tbiquinol-crtochrone c reductase conplex 11 bDa protein"

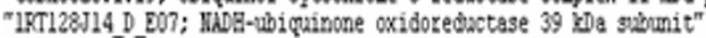

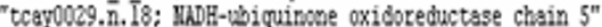

"tcav0038.i.18; MaDH-ubiquinone oxidoreductase chain 2"

"tcay0032.p.08; MaDH-vbiquinone oxidoreductase chain i "

"tcay0005.j.13: Sorting and asseably aachivery coaponent 50 houolog"

"IRTI58607 A D04; MADA-ubiquinone oxidoreductase chain 4"

"tccbk0005.0.0.

"IRT60:18 C G09; Cyrochrone c oxidase subunit 3 "

"tcba0004.d.10; matH-wbiquinote oxidoreductsse $23 \mathrm{kDa}$ suburit"

"IRT119E15 A C08; ATP-binding cassette sub-fanil î neuber 2"

"1RT38418 $\bar{c}$ Ğ09; Single-stransed DNA-binding protein"

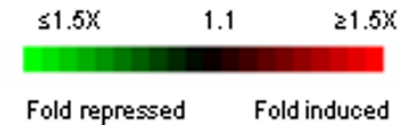

\section{Figure 8}

Supervised clustering of SAM selected genes belonging to cluster II and involved in mitochondrion biogenesis and activity. Columns as in figure 2 .

input for GoMiner did not encompass the whole of genes present in our membrane only a subset of genes contained in cluster I-IV was selected for GoMiner analysis. Nevertheless, in agreement with the detailed identification of the genes contained in the different clusters (see above), the GoMiner notably highlighted an enrichment of cluster I for genes regulating protein degradation while cluster II was found to be enriched for genes involved in RNA metabolism (and more particularly rRNA metabolism), ribosome biogenesis, mitochondrion, translation and protein folding (Fig. 12). On the other hand, cluster III was particularly found to be enriched for genes participating in actin cytoskeleton and myofibrillar organisation (Fig. 12). This functional categorization was supported by probability values (Fig. 12) which yielded the measure of the likelihood that a particular biological process was overrepresented in a cluster compared with that expected by random selection from the SAM list.

\section{Transcriptional regulators induced during muscle recovery growth}

Some of the genes induced during muscle recovery growth were themselves regulators of transcription (Fig. 13). Among those present in cluster II, were two cyclic AMPdependent transcription factors closely related to CREB3 and to ATF4 respectively, MEF2a, SF-1/fushitarazu homolog 1 related protein, cell growth regulating nucleolar protein LYAR, apoptosis-antagonizing transcription factor AATF and an unidentified zinc finger protein encoding gene. Cluster III included MTF1, the LIM/homeobox protein Lhx8, the homeobox proteins Hox-C9 and Hox-B1, the LIM domain containing transcription factor LMO4, the Homeodomain only protein Hop, a CREB1 related protein, sox11 as well as four unidentified zinc finger protein encoding genes. In addition to transcriptional regulators that trigger gene-specific expression by binding to sequence of promoters, we found other genes overexpressed during muscle recovery growth which potentially control gene expression by inducing histone modifica- 


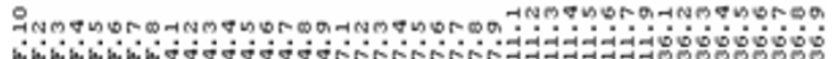

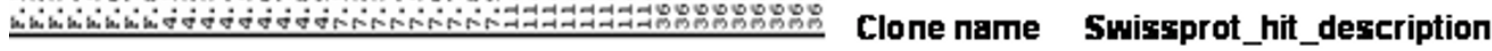

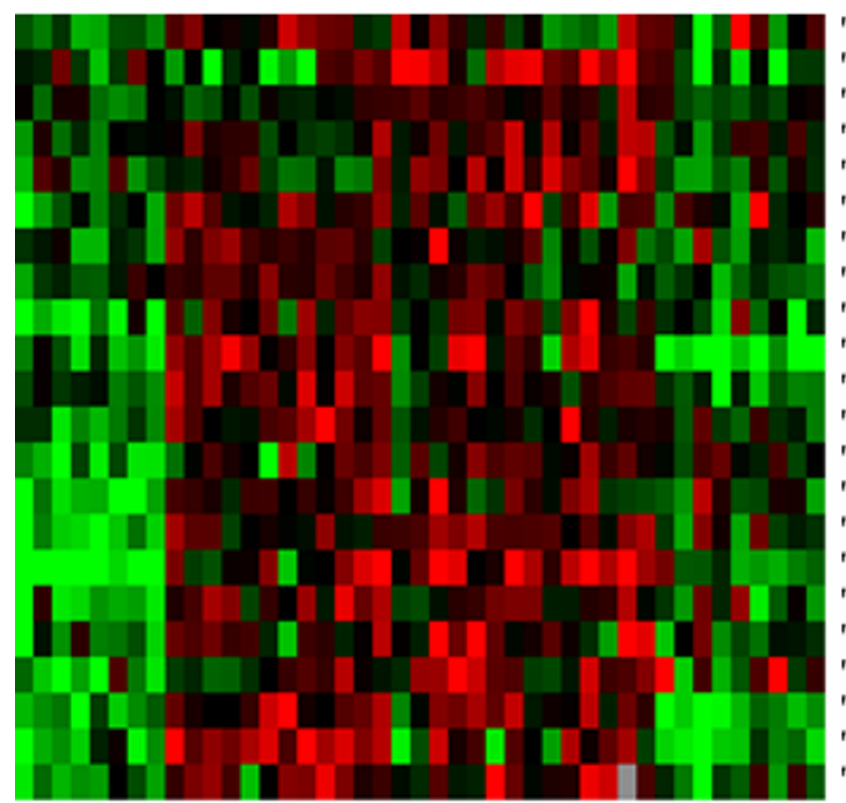

"tcay0005.e.06; DNh topoisonerase I "

"tcay0032.1.22; Histone H5A"

"tcac0006.b.21; Histone $\mathrm{H}^{\prime \prime}$

"tcab0001.p.03; CDK5 regulatory subunit-associated protein 3 "

"tcab0002.a.24; Hitogen-activated protein kinase $9 "$

"tcbk0055.p.10; I-phase inducer phosphatase 2 "

"tcbk0011.d.17; Origin recognition conplex subunit 4"

"tcba0003.p.18; Tuar protein D53 honolog "

"IRT86M16 C G08; Pelota honolog"

"IRT68H15 BDD8; Proliferation-associated protein 2G4"

"tcad0003.f.12; Chronobox protein homolog 3 "

"tcbi0012.1.16; Inportin alpha-2 subunit"

"tcba0015.1.01; DNA replication licensing factor $\mathrm{NCH}$ "

"IRT95D12 D B06; Regulator of chronosone condensation "

"tcay0008.h.02; DNA2-like honolog "

"IRT143J10 D E05; G1/\$-specific cyclin D2"

"tcay0039. $\overline{\mathrm{e}} . \overline{\mathrm{O}} 3$; Histone H2A.z"

"tcab0001.i.20; DNh replication licensing factor MCH6 "

"tcbk0010.0.13; Septin-? (CDC10 protein hosolog)"

"IRT143F12 D C06; Veel-like protein kinase"

"IRT38M18 $\bar{C}$ Ḡ09; Single-stranded DM-binding protein"

"tcay0018.f.15; Chaperone protein dnat"

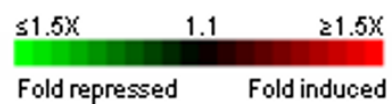

Figure 9

Supervised clustering of SAM selected genes belonging to cluster II and involved in cell division and chromatin assembly. Columns as in figure 2 .

tions (SmyD1) or DNA modification (DNMT1 and DNMT2).

\section{Validation of the microarray gene expression data}

The accuracy and reliability of the results obtained with microarrays were tested by quantitative RT-PCR (Q-PCR) of 10 selected genes belonging to different functional classes. The gene expression levels obtained by Real-time PCR were normalized to that of the $18 \mathrm{~s}$. A good agreement was observed between microarray and Q-PCR analysis (Fig. 14) with discordant results obtained for only two genes. Thus, differential expression detected by microarray analysis is highly predictive of expression levels measured with an independent methodology such as Q-PCR (80\% confirmation).

\section{Discussion}

In this study we used high density cDNA arrays to describe the changes in gene expression during muscle recovery induced by a fasting-refeeding sequence. Statistical analysis of the microarray data and transcriptional profiling led to the identification of 4 major temporally distinct clus- ters. The detailed identification of the genes contained in each cluster along with a Gominer analysis showed that these clusters contained genes involved in distinct biological functions.

In agreement with the proteolytic and lypolytic responses to starvation described in mammals [14] a large set of genes overexpressed in the muscle of fasted trout and down-regulated after refeeding, revealed an adaptation program that favours fatty acid oxidation and protein degradation to fuel metabolism. Two pathways of proteolysis appeared to be mobilized in the muscle of fasted trout: the lysosomal system as revealed by the up-regulation of several cathepsins and the ubiquitin-proteasome system, as indicated by the overexpression of numerous components involved in its activity. On the other hand, in agreement with a previous report showing that transcripts of calpains are not changed in muscle proteolysis of gravid trout [15], calpain genes were not found to be up-regulated in fasted trout muscle. Overall our data are consistent with the notion that most of the accelerated proteolysis in muscle is due to an activation of the Ub-proteasome pathway 


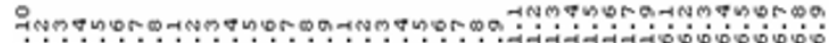
hish hish

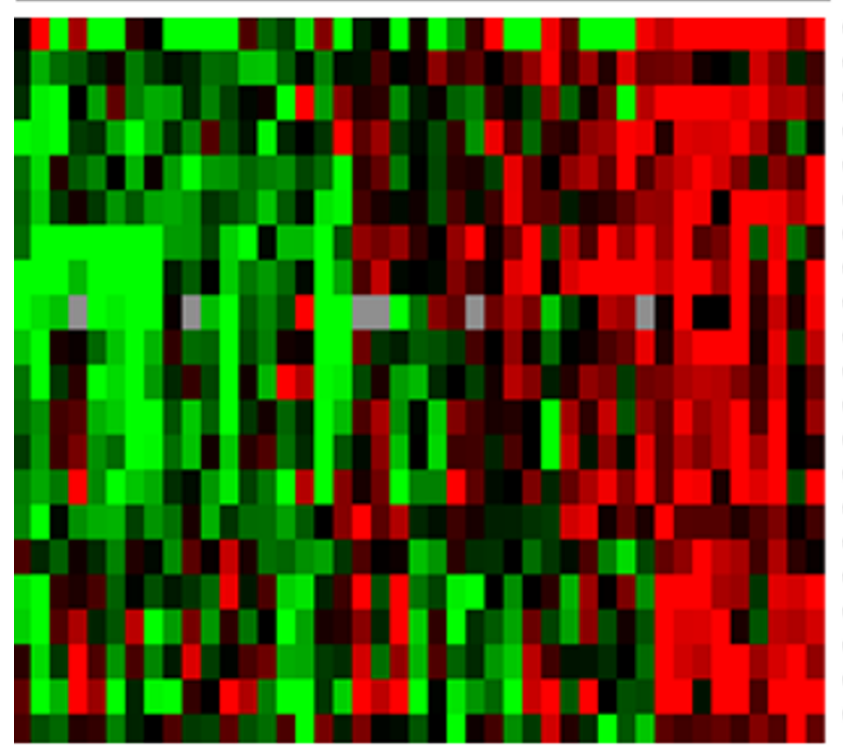

Clone name Swissprot_hit_description

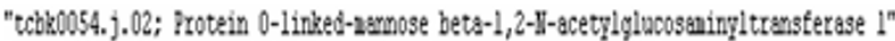

"tcaroucos.i.10; Inositol 1,4,5-trisprosphate recepptor the 3 "

"tcarousos.2.09; Hene crygenase "

"tcar0005.2.01; Crtochtone P450 28. "

"IRT28001 a D01; Oxpsterol-bindiry protein 1"

"ccblo0018.h.03; Tristin"

"tcbb0003.b.22; Exostosin-2 "

"tcbb00e?.1.13; Pesicle trafticking protein sec226 "

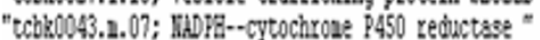

"tcary0000.j.18; Protein-S-isopremplcysteine 0-2ethyltransferase "

"tcbb0061.a.10; Lor-density lipoprotein receptor-related protein 2 precursor "

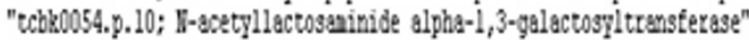

"tcbb0052.8.04; Trafficking protein particle conplex subusit 68"

"tccbb0039.p.01; Golyi sth? receptor conplex nenber 1"

"tcba0009.d.08; Apolinoprotein B-100 precursor "

"tcara0009.i.15; Conserved oligoneric Golgi conylex conponent ? "

"tcarpo001.n.07; Beta-1,4 I-acetrylgalactosanirglttransterase "

"tcar0003.a.09; Protein transport protein Sec20"

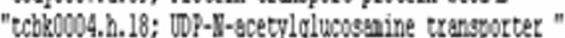

"ccba0002.c.04; Golgyi apparatus protein 1 precursor "

"ccar0004.i.17; Simal recogmition particle receptor alpha sibumit "

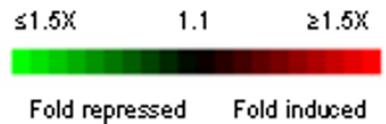

Figure 10

Supervised clustering of SAM selected genes belonging to cluster III and IV and involved in reticulum and Golgi dynamics. Columns as in figure 2 .

[16]. Supporting an increased protein degradation relative to synthesis due to food deprivation, starved trout muscle contained high levels of the transcript for tuberous sclerosis component 2 (TSC2) which has been shown, in mammals, to inhibit mTOR a positive regulator of cell growth and proliferation [17], and of the transcript encoding the translational repressor 4E-BP1, which presumably reinforces the inhibition of cap-dependent translation resulting from inactivation of Akt/mTOR [17].

Most of the genes that were up-regulated during muscle recovery growth fell into three major clusters (II-IV) with distinct temporal profiles and showed remarkable consistency in their functional categories. Cluster II which corresponds to the first phase of muscle recovery contained a large set of genes that stimulate cellular biosynthesis. This cluster included genes involved in transcript processing, translation or involved in ribosome production. A large number of genes was also found in this cluster that are involved in post-translational modifications of nascent proteins such as heat shock proteins, subunits of the chaperonin containing t-complex polypeptide 1 and peptidylprolyl cis trans isomerases that are chaperone enzymes which alter the peptide bond between a given amino acid and a proline, changing it from the cis to the trans conformation and vice versa. Interestingly, it has been previously reported in zebrafish that the heat shock protein hsp90 alpha not only participates in the correct protein folding but also plays a specific role in the normal process of myogenesis [18]. Given that hyperplasia (neosynthesis of myofibres) contributes to muscle growth in fish [19], it can be speculated that an elevated level of hsp 90 alpha in recovering muscle is at least in part related to the differentiation of neomyofibres. Several genes up-regulated during muscle recovery encode protein regulating the cell cycle and mitosis. This suggests, in agreement with a previous work carried out in the Antarctic fish Notothenia coriiceps [2] that cell proliferation is stimulated by feeding, increasing myoblast fusion into new myotubes (hyperplasia) and providing a source of nuclei as muscle fibres increase in diameter (hypertrophy). Consistent with cell cycle progression and cellular growth, which require adjustment in mitochondrial ATP production, cluster II was found to contain several transcripts that encode proteins required for oxidative respiration and ATP synthesis or involved in mitochondrial biogenesis. 


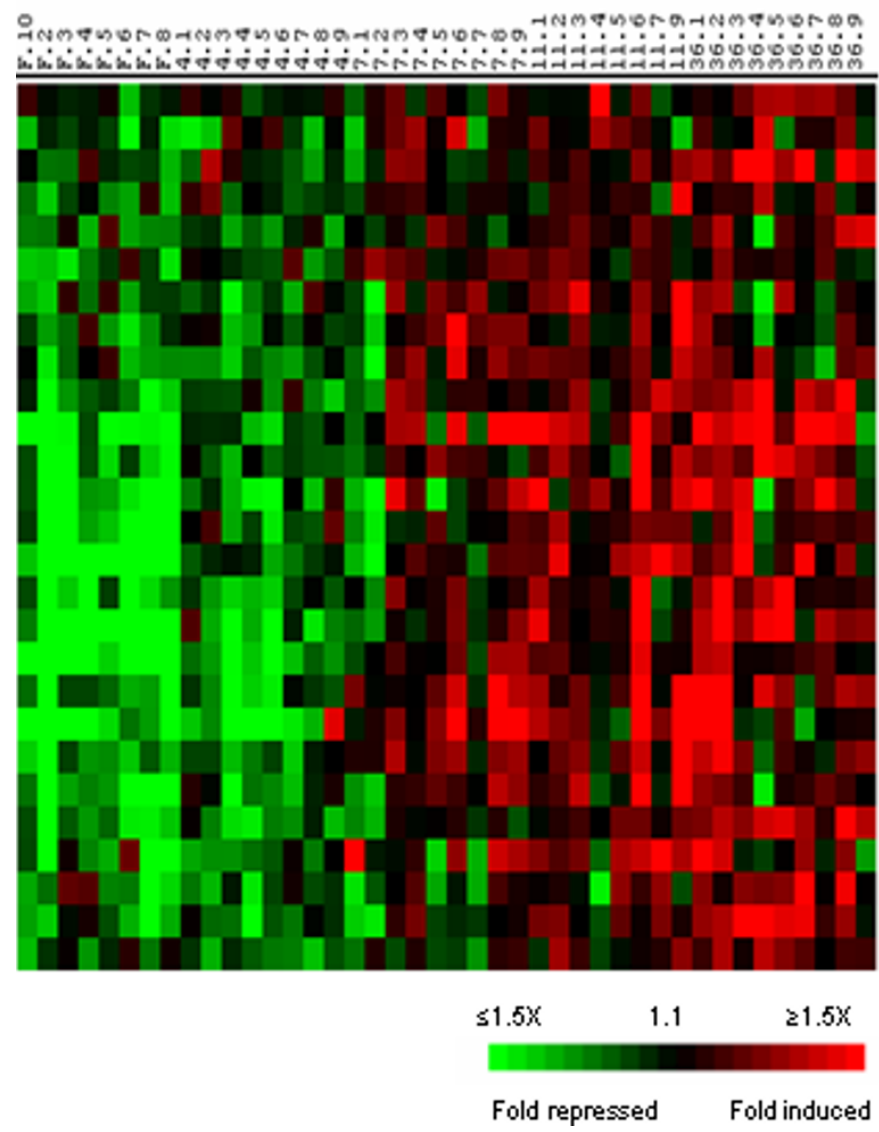

\section{Clone name Swissprot_hit_description}

"tcay0007.a.23; Ankyrin-2 "

"IRT94E22 C C11; Wuscle II-line assenbly protein unc-89 "

"tcay0013.p.11; TRI0 and F-actin binding protein"

"tcay0026.a.23; Dynactin subumit 6 "

"IRT30H09_B_DO5; F-actin capping protein beta subuit"

"tcad0007.c.04; Actin-like protein 3 (Actin-related protein 3)"

"tcbk0059.g.19; Nebulin"

"IRT144L05 B P03; Troponin C, skeletal uuscle "

"IRT73002 C $\bar{C}$-01; Troponin $C_{s}$ skeletal auscle"

"IRT69B20 D. A10; lyosin light chain 1, skeletal wuscle isofon"

"tcay0003.i.17; Myosin light chain 1, cardiac wuscle"

"tcay0001.n.05; Ankyrin-3"

"tcan0001.c.17; Nyosin heavy chain, cardiac auscle beta isoton "

"tcan0001.a.14; Actin, alpha cardiac "

"tchb0035.n.17; Actin, alpha skeletal auscle"

"IRT140B09 B D05; Nyosin light polypeptide 6 "

"tchk0038.

"IRT74D04 D B02; llyosin light polypeptide 6 "

"tcad0006.d.20; Hyosin regulatory light chain $2^{\prime \prime}$

"tcbk0010.a.14; Troponin T, cardiac auscle isofons"

"tcac0006.c.23; Hyosin regulatory light chain 2"

"tcblo0048.c.24; Troponyosin alpha 4 chain"

"1RT38:12 D P06; Dystrophin"

"tcay0025.b.11; Troporyosin 1 alpha chain "

"tchb0051.0.15; Actin-related protein $2 / 3$ coaplex subuit 3 "

"tchb0052.1.21; Hyosin-10 "

"IRT28E04_C_CO2; Filanin-binding LII protein 1"

Figure I I

Supervised clustering of SAM selected genes belonging to cluster III and involved in cytoskeletal and myofibrillar organisation. Columns as in figure 2.

Cluster III contained genes associated with Golgi and reticulum dynamics. The induction of these genes, most of which participate in post-translational modifications and transport of proteins, is consistent with the enhancement, 4 to 11 days post refeeding, of the protein synthesis machinery. A striking feature of cluster III is the presence of a large set of genes encoding cytoskeletal proteins and sarcomeric proteins involved in contractile functions. At the same time are induced several transcripts encoding matrix compounds such as chains of the fibril forming collagen I which is the major collagen of intramuscular connective tissue in fish [20]. All these expressions that evoke the muscle regenerative response that follows cardiotoxin delivery in mouse [21] show that myofiber and muscle remodelling occur at a late time period of muscle recovery growth. As in cluster III, cluster IV contained genes regulating Golgi and reticulum biogenesis and activity but differed by the presence of genes with a role in carbohydrate metabolism and lipid biosynthesis. The increased expression in recovering trout muscle of genes involved in glycolysis is in agreement with recent data showing that atrophying muscle of gravid trout has low levels of transcripts encoding many glycolytic enzymes [15].

Among the transcriptional regulators induced in recovering muscle was found MEF2a. The transcription factors of the MEF2 family bind to an A/T rich sequence present in many muscle-specific promoters and enhancers [22]. Supporting a role of MEF2a in transcription of fish contractile protein encoding genes, MEF2 sites have been identified in carp myosin promoters [23] and MEF2a knockdown in zebrafish has been shown to induce a down regulation of a large set of transcripts for gene encoding contractile proteins such as troponins, myosin heavy and light chains and $\alpha$-tropomyosin [24]. Interestingly MEF2a induction in recovering muscle precedes that of the sarcomeric protein encoding genes. This temporal sequence is in accordance with a function of MEF2a in the burst of myofibrillar protein encoding genes activation observed during muscle compensatory growth. Also were induced Sox8, Sox 11 and the LIM-only protein gene LMO4. All these genes are 


\section{Cluster}

\begin{tabular}{|c|c|c|c|c|}
\hline & I & II & III & $\mathbf{N}$ \\
\hline Protein catabolism & $p<0.0046 \quad 25$ & 5 & 4 & \\
\hline Ubiquitin cyde & $p<0.005 \quad 32$ & 10 & 4 & \\
\hline acyl-CoA dehydrogenase & $p<0.041 \quad 4$ & 0 & 0 & \\
\hline rRNA metabolism & 3 & $p<0.0001$ & 1 & \\
\hline mRNA metabolism & 12 & $p<0.0003$ & 2 & \\
\hline ribosome biogenesis & 4 & $p<0.0001$ & 1 & \\
\hline protein folding & 11 & $p<0.0005$ & 5 & \\
\hline mitochondrial part & 14 & $p<0.0018$ & 7 & \\
\hline translation & 16 & $p<0.0049$ & 8 & \\
\hline chromatin & 5 & $p<0.0001$ & 2 & \\
\hline DNA-dependant DNA replication & 0 & $p<0.028$ & 2 & \\
\hline actin cytoskeleton and myosin & 7 & 4 & $p<0.0015 \quad 13$ & \\
\hline ER-Golgi intermediate & 0 & 0 & $p<0.0125$ & \\
\hline Golgi membrane & 2 & 0 & 0 & $p<0.0001$ \\
\hline glyoolysis & 0 & 0 & 0 & $p<0.0007$ \\
\hline
\end{tabular}

Figure 12

Ontology-matrix showing functional grouping of genes belonging to clusters I-IV. The enrichment of genes of a given functional class is indicated for each cluster. Also are represented the $\mathrm{p}$-values. Dark and light colors represent $\mathrm{P}$-values of $<0.005$ and $<$ 0.05 respectively

expressed in the fish differentiating embryonic myotome [[25] and [26]; Dumont and Rescan: unpublished results] suggesting that their expression in recovering muscle relates to the formation of new differentiating muscle fibres. Also the induction of Hop (Homeodomain only protein) in trout recovering muscle is of interest because Hop has been recently reported in mammals to regulate skeletal myoblast differentiation and to play a critical role in muscle regeneration [27]. The induction of three cyclic AMP-responsive element binding proteins (ATF4, CREB1 and CREB3) along with CAMP-dependent protein kinase subunits suggests a possible role of cyclic AMP signalling in the recruitment of new myofibres during muscle recovery. Supporting this view, it has been reported in amniotes that the CAMP pathway participates in the regulation of myogenesis [28] involving a CREB-mediated transcription [29] and that ATF4 is induced during in vitro differentiation of human skeletal myoblasts [30]. In addition to the induction of transcriptional regulators that exert their function at the nuclear genome level, we observed the up- regulation of the transcription factor A that is a key activator of mitochondrial transcription and a participant in mitochondrial genome replication [31] Several other genes up-regulated during muscle recovery growth fall within the transcriptional regulator class. These genes either have homology to known sequences, but no demonstrated function in muscle development and growth (for example: LYARR, the leucine zipper containing factor AATF and PU.1) or have no homology to any known sequence (in particular most of the zinc finger protein genes). All these genes deserve in-depth studies: it would be of interest in particular to identify their individual function in fish muscle development and growth using antisens morpholino oligonucleotides and to further characterize their gene targets. In addition to the up-regulation of transcription factors, some genes related to chromatin remodelling or DNA modification also were found to be induced in recovering muscle. Thus we observed the induction of the chromatin remodelling protein SmyD1 and that of two DNA (cytosine-5) methyl transferases 


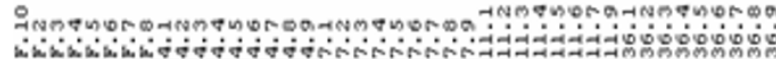

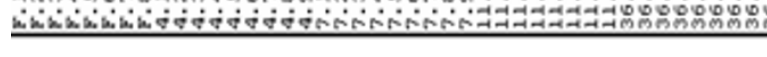

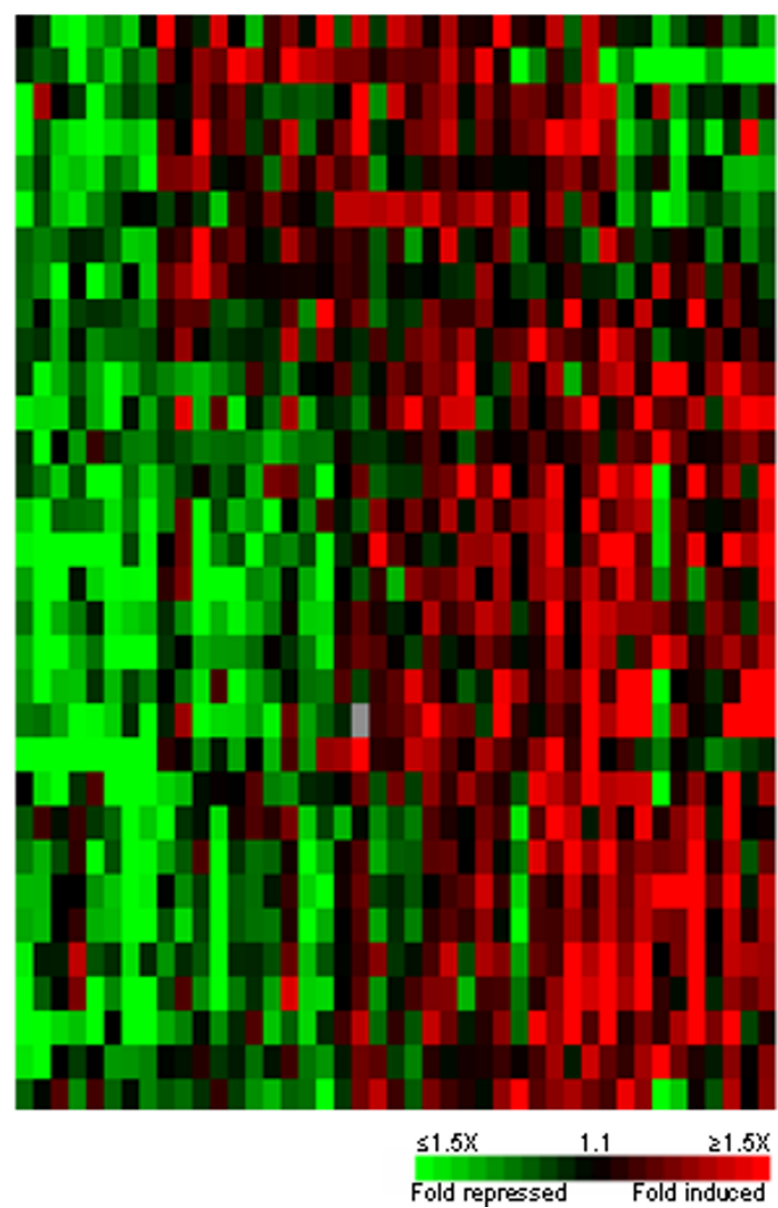

\section{Fold repressed Fold induced}

\section{Clone name Swissprot_hit_description}

tcba0021.a.12; Transcription factor $\mathbf{A}$, witochondrial precursor " tcbk0010.1.11; Apoptosis-antagonizing transcription factor" tcad0001.b.13; Cyclic AMP-responsive elenent binding protein 3 " IRT68P15 B H08; Cyclic-AKP-dependent transcription factor ATF-4 " IRT90K01_A_FO1; Fushitarazu factor 1 related protein" (SF-1) tcbk0026.j.04; Myocyte-specific enhancer factor $2 \mathrm{~A}^{\prime \prime}$ tcba0010.1.24; Zinc finger protein"

tcay 0036. a.02: Transcription factor $50 \mathrm{X}-8^{\prime \prime}$

1RT32B18_D_A09; Transcription factor \$pi-1/ PU.1 " tcay0039.1.01: Suppressor of hairless protein" tcbk0035.k.02; Forkhead box protein Fox03h" tcay0012.1.10; 2inc finger protein" IRT147M06_C_G03; Paired box protein Pax-2" tcba0027. $\bar{h} . \overline{0}$; High mobility group-T protein" tcay0010.c.03: Hetal-requlatory transcription factor 1 " tcaa0001.n.17; DMA (cytosine-5)-wethyltransferase 1 " tcay0031.k.08; DNh (cytosine-5)-wethyltransferase-like protein 2 " tcaY0033.p.11: Trist related protein $2^{\prime \prime}$ tcay0004.1.20; Rest corepressor $1^{\text {" }}$ IRT112B16_D_A08; LIM/howeobox protein Lhx8 " tcay0012. $\bar{h} . \overline{0}$; Zinc finger protein : tcaY0031.k.23; Cell growth-regulating nucleolar protein LYA" 1RT50C19_A_B10: Transcription factor \$0X-11" tcbk0049.g.21; Zinc finger protein " tcbk0057.1.12; Zinc finger protein" tcbk0061.a.18; Honeobox protein Hox-C9" tcbio060.j.05; cAllP response elenent binding protein 1 tcbk0015.n.12; Honeobox protein Hox-B1" tcbk0030.e.04; Hairy/enhancer of split related with YRPW notif $2^{\prime \prime}$ tcbk0027.g.01; Honeodonain-only protein" IRT163P20_D_H10; LIM dowain transcription factor LH04" tcay0003.e. 08 ; Histone wethyl transterase suydl"

\section{Figure 13}

Supervised clustering of SAM selected genes induced during muscle recovery growth and involved in transcriptional regulation. Columns as in figure 2.

(DNMT1 and DNMT2). SmyD1 has been recently shown to have a major role in myofibril organisation in the zebrafish embryo [32]. Consistent with such a function in recovering trout muscle it is interesting to note that SmyD1 is coexpressed with genes encoding sarcomeric proteins. In relation to a function for DNMT1 in muscle growth, it has been reported that forced expression of DNMT1 in murine C2C12 myoblasts causing de novo methylation in the MyoD gene induced its expression and stimulated myogenesis [33].

\section{Conclusion}

Our microarray analysis shows that genes overexpressed in recovering muscle fall into distinct groups with distinct temporal profiles which showed remarkable consistency in their functional classes. The early phase of muscle recovery was associated with dramatic transient induction of a large number of genes functionally related to RNA processing, translation, maturation of proteins, ribosome biogenesis, cell proliferation and mitochondrial bioenergetics. In a later and more sustained phase several genes regulating Golgi and reticulum dynamics and genes involved in muscle remodelling were induced. The generation of a database of novel genes associated with muscle recovery growth will help investigations on genes, pathways or cellular process involved in muscle growth and regeneration.

\section{Methods}

\section{Animals and experimental design}

Investigations were conducted in agreement with the guiding principles for the use and care of laboratory animals and in compliance with European regulations on animal welfare. A spring strain of l-year-old rainbow trout 

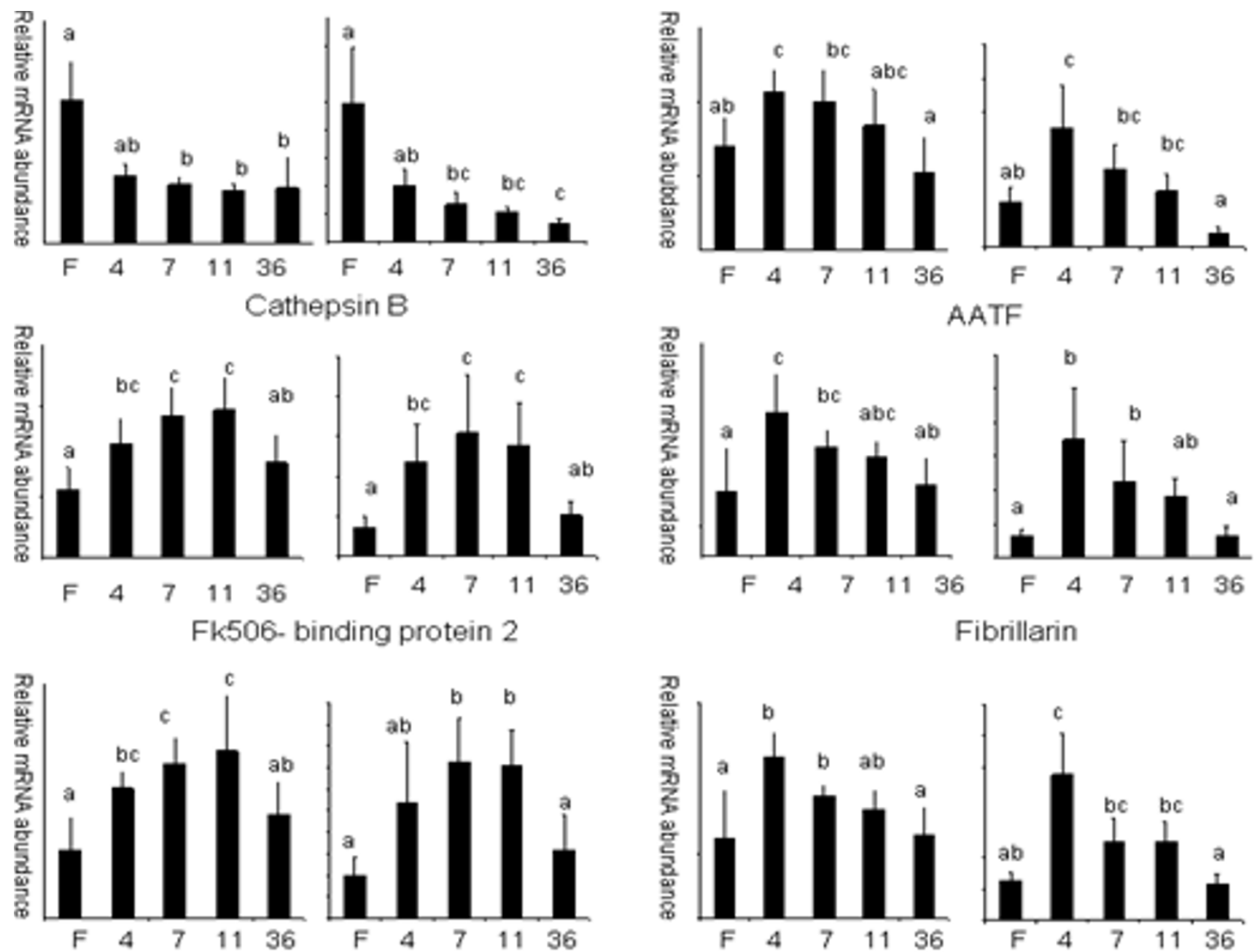

\section{Density Regulated Protein}
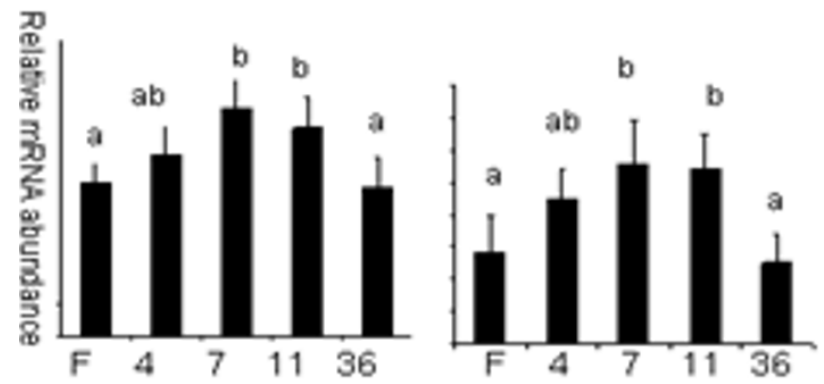

$\operatorname{mef} 2 a$

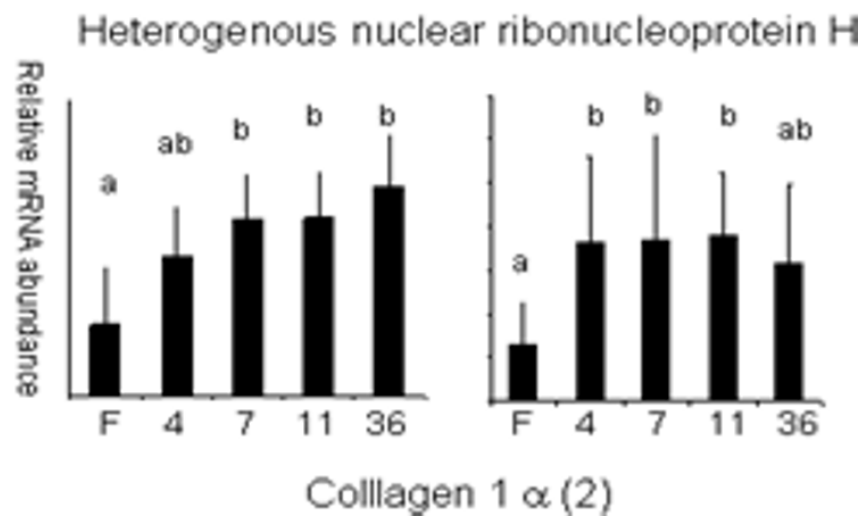

Figure 14

Relative mRNA expression levels of selected genes in muscle from fasted (F), 4 (4), 7 (7), II (I I) and 36 (36) day-refed trout as obtained by microarray hybridisation (left) and Q-PCR (right). The mRNA levels measured by Q-PCR were normalized to levels of I8S rRNA. Bars sharing the same letter(s) are not significantly different $(p<0.05)$.

(Oncorhynchus mykiss) was used. The fish had been fed to satiation with a commercial diet until the beginning of the starvation. The fasted group was composed of fish initially weighing about 130 grams that were deprived of food for 30 days. Refed groups were composed of trout from the fasted group that were fed at a rate three time higher than 
the normal ration and sampled sequentially at $4,7,11$ and 36 days post refeeding. Fish were reared in freshwater tank (PEIMA-INRA, Sizun, France) under a natural photoperiod. The water temperature was $11.8^{\circ} \mathrm{C}$ at the end of starvation, $11.1^{\circ} \mathrm{C}, 10.5^{\circ} \mathrm{C}, 10.4^{\circ} \mathrm{C}$ and $7.8^{\circ} \mathrm{C}, 4,7,11$ and 36 days post refeeding respectively. The fish were rapidly anaesthetized with phenoxy-ethanol (Aquaveto, $4 \mathrm{ml}$ per 10 liters of fresh water) before dissection. The condition factor (an indicator of the body shape) was calculated as follows: $\mathrm{K}=$ body weightx100/body length ${ }^{3}$ (the body length did not include the caudal fin length).

\section{RNA purification and complex cDNA target preparation}

Muscle from 8 or 9 trout was sampled for each time point. A transverse slice of fast muscle situated just beneath the dorsal fin was taken for RNA extraction. Total RNA was purified using TRIzol reagent (Invitrogen, Carlsbad, CA). The RNA integrity and concentration were respectively controlled and calculated with the Agilent bioanalyser. Complex target were prepared from $5 \mu \mathrm{g}$ of RNA of each sample by simultaneous reverse transcription (using oligo(dT) as primer) and labelling for 2 hours at $42^{\circ} \mathrm{C}$ in the presence of $30 \mu \mathrm{Ci}$ [alpha-33P] dCTP, $120 \mu \mathrm{M} \mathrm{dCTP,}$ $20 \mathrm{mM}$ each dATP, dTTP, dGTP and 400 units Superscript II reverse transcriptase (Invitrogen). RNA was degraded by treatment at $68^{\circ} \mathrm{C}$ for 30 min with $1 \mu$ l 10\% SDS, l $\mu$ l 0.5 $\mathrm{M}$ EDTA and $3 \mu \mathrm{l} 3 \mathrm{M} \mathrm{NaOH}$, and then equilibrated at room temperature for $15 \mathrm{~min}$. Neutralization was done by adding $10 \mu \mathrm{l} 1 \mathrm{M}$ Tris-HCI plus $3 \mu \mathrm{l} 2 \mathrm{~N} \mathrm{HCl}$.

\section{cDNA microarrays production}

Nylon micro-arrays $(7.6 \times 2.6 \mathrm{~cm})$ were obtained from the INRA-GADIE resource centre [34]. A set of 9023 distinct rainbow trout cDNA clones originating from pooled-tissues libraries $[35,36]$ were amplified by PCR using primers specific of the polylinker sequence of the vectors. Quality of the amplification products was systematically checked on $1 \%$ agarose gels. Unpurified PCR products were evaporated, resuspended in $20 \mu$ l of distilled water, then transferred to 384-well microplates and spotted onto nylon membranes (Hybond-N+; Amersham Biosciences, Saclay, France). The last step was conducted using a Biorobotics MicroGrid-II arrayer (Genomics Solution, Cambridge, U.K.) equipped with a 64-pins Biorobotics printhead and 64 Biorobotics $100 \mu \mathrm{m}$ solid pins. The spotted DNA were denaturated in $150 \mathrm{mM} \mathrm{NaOH}, 1.5 \mathrm{M}$ $\mathrm{NaCl}$. A neutralisation step was performed in $1 \mathrm{M}$ Tris $\mathrm{HCl}$ (pH 7.5), $1.5 \mathrm{M} \mathrm{NaCl}$. A last step to rinse micromembranes in $2 \times$ SSC was performed. The DNA was subsequently fixed by successive heat $\left(80^{\circ} \mathrm{C}\right.$ during 2 hours $)$ and UV $(120000 \mu \mathrm{J})$ treatments.

\section{Hybridisation}

A first hybridization was performed using a 33P-labelled oligonucleotide (TAATACGACTCACTATAGGG) which is found at the extremity of each PCR product to monitor the amount of cDNA present in each spot. After stripping (3 hours $68^{\circ} \mathrm{C}, 0.1 \mathrm{SSC}, 0.2 \%$ SDS), arrays were prehybridized for $4 \mathrm{~h}$ at $65^{\circ} \mathrm{C}$ in hybridization solution (5× Denhardt's, 5 SSC, $0.5 \%$ SDS) and hybridized with denatured labeled cDNAs for $48 \mathrm{~h}$ at $65^{\circ} \mathrm{C}$ in hybridization solution. After 3 washes $\left(1\right.$ hour $68^{\circ} \mathrm{C}, 0.1$ SSC $0.2 \%$ SDS ), arrays were exposed for 65 hours to phosphor-imaging plates before scanning using a FUJI BAS 5000. Signal intensities were quantified using BZScan software [37].

\section{Microarray signal processing}

Low oligonucleotide signals (lower than three times the background level) were excluded from the analysis. After this filtering step, signal for each spot was divided by the hybridisation signal obtained with the vector oligonucleotide. After this correction, signals were then normalized by dividing each gene expression value by the median value of the array.

\section{Microarray data analysis}

SAM software [10] was used to identify genes differentially expressed between muscle of fasted trout and muscle of 4, 7, 11 and 36 day refed trout. For each comparison a false discovery rate (FDR) of $0.01 \%$ was used. All genes identified in at least one of the above comparisons were kept for clustering analysis in order to characterize the temporal expression profiles of statistically relevant genes. For supervised clustering analysis, data was log transformed, median-centred and an average linkage clustering was carried out using CLUSTER software and the results were visualized by TREEVIEW [11].

\section{Data mining}

Rainbow trout sequences originating from INRA Agenae [35] and USDA [36] EST sequencing programs were used to generate publicly available contigs [38]. The 8th version (Om.8, released January 2006) was used for Blast X comparison against the Swiss-Prot database (January 2006) [39]. The score of each alignment was retrieved after performing a BlastX comparison. In addition, for each EST spotted onto the membrane, the accession number of the corresponding rainbow trout cluster (Unigene Trout, January 2006), if any, was retrieved from the UniGene database [40].

\section{Gene Ontology analysis}

In order to assign functional categories to each identified clusters, we used GoMiner software [13]. For each PCR product spotted, the corresponding contig was blast against Swissprot Database (a score $>86$ was considered as significant). Then the SwissProt accession number was used as the input to analyse gene lists of clusters for GO categories that showed statistically enrichment (2265 genes obtained by SAM analysis as total genes list). P-val- 
Table I: Sequence of the primer pairs used for real-time quantitative PCR and gene names.

\begin{tabular}{lll}
\hline Abbreviated name & Sequence & Target gene \\
\hline HNNP-FW & GTAGAGCTGGAGTCGGAGGA & Heterogeneous nuclear ribonucleoprotein H \\
HNNP-RV & CCTCAGTCTCTGGGCAGTTT & \\
MEF2A-FW & GCTCAGGCCTCCTTACACAG & Myocyte enhancer factor 2a \\
MEF2A-RV & ACTTGGTGGGCATGACTTTC & \\
DRP-FW & AGGTCCGGTAGGAAATGCTT & Density Regulated Protein \\
DRP-RV & ACGGGGGATTTTAGCTATCG & Fibrillarin \\
FBL-FW & AAACCTGGCTCGAAGGTCAT & \\
FBL-RV & TGGTTCTCTTTTTGGCAACG & FK506-binding protein 2 \\
FK506bp2-FW & CCTGCTCGGAATGTGTGAG & \\
FK506bp2-RV & AAGTCAGACCTCCTCTCGATG & Apoptosis antagonizing transcription factor \\
AATF-FW & CATTCAGAAGCTCCGCAGTA & \\
AATF-RV & TCCCGAATAGTGAGCGAAAC & Cathepsin B \\
Cathps-FW & CTCAGACCGCGTGTGTATCC & \\
Cathps-RV & GACCAGCCCCTCTTTAGTCC & Collagen I alpha 2 chain \\
Coll I $\alpha 2-F W$ & CTCGAGTCTGCGTGGACAT & \\
Coll I $\alpha 2-R V$ & GTCCGATAGCACCATGACCT & \\
\hline
\end{tabular}

ues were estimated by two-sided Fisher's exact test and only $\mathrm{P}<0.05$ were retained.

\section{Real-time PCR analysis}

The expression of 10 selected genes belonging to different functional classes was analysed by real-time RT-PCR. Total RNA $(2 \mu \mathrm{g})$ from all samples used for microarray analysis were reverse transcribed using 200 Units of moloney murine Leukemia virus (MMLV) reverse transcriptase (Promega) and $0.5 \mu \mathrm{g}$ random hexamers (Promega) per $\mu \mathrm{g}$ of total RNA according to manufacturer's instruction. The expression levels were determined using the I-cycler IQ (Biorad, Hercules, CA) instrument. Briefly reverse transcription products were diluted to $1 / 24$ and $5 \mu$ l were used for each real-time PCR reaction which were performed using a real-time PCR kit provided with a SYBR Green fluorophore (Eurogentech, Belgium). For each target gene, primers (Table 1) were chosen to presumably flank an intron as determined by comparison with the gene sequence of zebrafish ortholog. The amount of the target RNA was determined by comparison with a standard curve generated using serial dilution of RT reactions. This dilution curve was used to ensure that PCR efficiency ranged from 90 to $100 \%$ and that amplification was linear within sample set. The level of 18S RNA in each sample was also measured by real-time RT-PCR and used for target genes abundance normalisation within sample set. Statistical analysis were performed using Statistica 7.0 software (Statsoft, Tulsa, OK). Differences between samples were analysed using non parametric Kruskal-Wallis test.

\section{Authors' contributions}

PYR coordinated the study, analysed the data and wrote the manuscript. JM and AL performed microarray experi- ments and participated in the data analysis. CR performed RNA extractions and Real-time PCR. DE and KH prepared the microarrays. All authors read and approved the final manuscript.

\section{Acknowledgements}

This work was supported by grants from the Institut National de la recherche Agronomique, L'OFIMER, I'IFOP and the CIPA. We thank Lionel Goardon for fish rearing and sampling, Yann Guiguen for help in data analysis and the INRA-SIGENAE group (Toulouse, France) for bioinformatic support.

\section{References}

I. Hornick JL, Van Eenaeme C, Gerard O, Dufrasne I, Istasse L: Mechanisms of reduced and compensatory growth. Domest Anim Endocrinol 2000, 19:121-132.

2. Brodeur JC, Peck LS, Johnston IA: Feeding increases MyoDand PCNA expression in myogenic progenotors cells of Notothenia coriiceps. J Fish Biol 2002, 60: 1475-I485.

3. Fauconneau $B$, Paboeuf $G$ : Effect of fasting and refeeding on in vitro muscle cell proliferation in rainbow trout (Oncorhynchus mykiss). Cell Tissue Res 2000, 301:459-463.

4. Koumans JT, Akster HA: Myogenic cells in development and growth of fish. Comp Biochem Physiol A 1995, I I 0:3-20.

5. Duan C: Nutritional and developmental regulation of insulinlike growth factors in fish. J Nutr 1998, I 28:306S-3 I4S.

6. Chauvigné F, Gabillard JC, Weil C, Rescan PY: Effect of refeeding on IGFI, IGFII, IGF receptors, FGF2, FGF6, and myostatin mRNA expression in rainbow trout myotomal muscle. Gen Comp Endocrinol 2003, 132(3):209-2I5.

7. Johansen KA, Overturf $\mathrm{K}$ : Alterations in expression of genes associated with muscle metabolism and growth during nutritional restriction and refeeding in rainbow trout. Comp Biochem Physiol B 2006, 144: I 19-127.

8. Gahr SA, Weber GM, Rexroad CE: Fasting and refeeding affect the expression of the inhibitor of DNA binding (ID) genes in rainbow trout (Oncorhynchus mykiss) muscle. Comp Biochem Physiol B 2006, I 44:472-477.

9. Coulibaly I, Gahr SA, Palty Y, Yao J, Rexroad CE: Genomic structure and expression of uncoupling protein 2 genes in rainbow trout (Oncorhynchus mykiss). BMC Genomics 2006, 7:203.

10. Tusher VG, Tibshirani R, Chu G: Significance analysis of microarrays applied to the ionizing radiation response. Proc Natl Acad Sci USA 200I, 98:5II6-5I2I. 
II. Eisen MB, Spellman PT, Brown PO, Botstein D: Cluster analysis and display of genome-wide expression patterns. Proc Natl Acad Sci USA 1998, 95: I 4863-14868.

12. Browseable file containing the average linkage clustering [http://www.sigenae.org/fileadmin/ temp/TreeView/ tous sam spearman.html]

13. Zeeberg BR, Feng W, Wang G, Wang MD, Fojo AT, Sunshine M, Narasimhan S, Kane DW, Reinhold WC, Lababidi S, Bussey KJ, Riss J, Barrett JC, Weinstein JN: GoMiner: a resource for biological interpretation of genomic and proteomic data. Genome Biol 2003, 4:R28

14. Finn PF, Dice JF: Proteolytic and lipolytic responses to starvation. Nutrition 2006, 22:830-844.

15. Salem M, Kenney PB, Rexroad CE, Yao J: Microarray gene expression analysis in atrophying rainbow trout muscle: $A$ unique non-mammalian muscle degradation model. Physiol Genomics 2006, 28:33-45.

16. Lecker SH, Jagoe RT, Gilbert A, Gomes M, Baracos V, Bailey J, Price SR, Mitch WE, Goldberg AL: Multiple types of skeletal muscle atrophy involve a common program of changes in gene expression. FASEB / 2004, 1 8:39-5।.

17. Lindsley JE, Rutter J: Nutrient sensing and metabolic decisions. Comp Biochem Physiol B 2004, I39:543-559.

18. Sass JB, Weinberg ES, Krone PH: Specific localization of zebrafish hsp90 alpha mRNA to myoD-expressing cells suggests a role for hsp90 alpha during normal muscle development. Mech Dev 1996, 54: 195-204.

19. Rowlerson A, Veggetti A: Cellular mechanisms of post-embryonic muscle growth in aquaculture species. In muscle development and growth, Fish Physiology series Volume 18. Edited by: Johnston IA. San Diego: Academic Press; 200I: 103-140.

20. Sato K, Yoshinaka R, Itoh Y, Sato M: Molecular species of collagen in the intramuscular connective tissue of fish. Comp Biochem Physiol 1989, 92:87-91.

21. Goetsch SC, Hawke TJ, Gallardo TD, Richardson JA, Garry DJ: Transcriptional profiling and regulation of the extracellular matrix during muscle regeneration. Physiol Genomics 2003 , | 4:26I-27|.

22. Gosset LA, Kelvin DJ, Sternberg EA, Olson EN: A new myocytespecific enhancer-binding factor that recognizes a conserved element associated with multiple muscle-specific genes. Mol Cell Biol 1989, 9(I I):5022-5033.

23. Kobiyama A, Hirayama M, Muramatsu-Uno M, Watabe S: Functional analysis on the 5 '-flanking region of carp fast skeletal myosin heavy chain genes for their expression at different temperatures. Gene 2006, 372:82-91.

24. Wang Y, Qian L, Dong Y, Jiang Q, Gui Y, Zhong TP, Song H: Myocyte-specific enhancer factor $2 A$ is essential for zebrafish posterior somite development. Mech Dev 2006, I23:783-79|

25. De Martino S, Yan YL, Jowett T, Postlethwait JH, Varga ZM, Ashworth A, Austin CA: Expression of Sox II gene duplicates in zebrafish suggests the reciprocal loss of ancestral gene expression patterns in development. Dev Dyn 2000, 21 7:279-292.

26. Lane ME, Runko AP, Roy NM, Sagerström CG: Dynamic expression and regulation by Fgf8 and Pou2 of the zebrafish LIMonly gene, Imo4. Mech Dev 2002, I I 9:SI85-SI89.

27. Kee HJ, Kim JR, Nam KI, Park HY, Shin S, Kim JC, Shimono Y, Takahashi $\mathrm{M}$, Jeong $\mathrm{MH}$, Kim $\mathrm{N}$, Kim KK, Kook $\mathrm{H}$ : Enhancer of Polycombl, a novel homeodomain only protein-binding partner, induces skeletal muscle differentiation. I Biol Chem 2007, 282:7700-7709.

28. Marchal S, Cassar-Malek I, Magaud JP, Rouaut JP, Wrutniak C, Cabello G: Stimulation of avian myoblast differentiation by triiodothyronine: possible involvement of the CAMP pathway. Exp Cell Res 1995, 220:1-10.

29. Chen $A E$, Ginty DD, Fan CM: Protein kinase A signalling via CREB controls myogenesis induced by Wnt proteins. Nature 2005, 433:317-322.

30. Sterrenburg E, Turk R, 't Hoen PA, Van Deutekom JC, Boer JM, van Ommen GJ, den Dunnen JT: Large-scale gene expression analysis of human skeletal myoblast differentiation. Neuromuscul Disord 2004, 14:507-18.

31. Asin-cayuela J, Gustafsson CM: Mitochondrial transcription and its regulation in mammalian cells. Trends Biochem Sci 2007, 32:111-117.
32. Tan X, Rotlland J, LI H, De Deyne P, Du SJ: SmyD I, a histone methyltransferase, is required for myofibril organization and muscle contraction in zebrafish embryos. Proc Natl Acad Sci USA 2006, 103:27|3-27I8.

33. Takagi $\mathrm{H}$, Tajima $\mathrm{S}$, Asano A: Overexpression of DNA methyltransferase in myoblast cells accelerates myotube formation. Eur J Biochem | 995, 23 I:282-291.

34. INRA-GADIE [http://www-crb.jouy.inra.fr]

35. Govoroun M, Legac F, Guiguen Y: Generation of a large scale repertoire of Expressed Sequence Tags (ESTs) from rainbow trout normalized cDNA libraries. BMC Genomics 2006, 7:196.

36. Rexroad CE 3rd, Lee Y, Keele JW, Karamycheva S, Brown G, Koop $B$, Gahr SA, Palti Y, Quackenbush J: Sequence analysis of a rainbow trout cDNA library and creation of a gene index. Cytogenet Genome Res 2003, 102(I-4):347-354.

37. Lopez IP, Milagro FI, Marti A, Moreno-Aliaga MJ, Martinez JA, De Miguel C: Gene expression changes in rat white adipose tissue after a high-fat diet determined by differential display. Biochem Biophys Res Commun 2004, 3 I 8:234-239.

38. Sigenae. Sigenae [http://www.sigenae.org]

39. Swiss-Prot [http://www.expasy.org/sprot/]

40. Unigene [http://www.ncbi.nlm.nih.gov/UniGene/]
Publish with Biomed Central and every scientist can read your work free of charge

"BioMed Central will be the most significant development for disseminating the results of biomedical research in our lifetime. "

Sir Paul Nurse, Cancer Research UK

Your research papers will be:

- available free of charge to the entire biomedical community

- peer reviewed and published immediately upon acceptance

- cited in PubMed and archived on PubMed Central

- yours - you keep the copyright
BioMedcentral 